\title{
Uma Ontologia de Referência para Autorização Orçamentária e Execução da Despesa Pública
}

\section{Title: A Reference Ontology for Budgetary Authorization and Execution of Public Expenditure}

\author{
Archimedes A. Detoni ${ }^{12}$, Lucas Bassetti R. da Fonseca ${ }^{2}$, \\ João Paulo A. Almeida', Ricardo de Almeida Falbo'
}

Departamento de Informática - Universidade Federal do Espírito Santo (UFES) Av. Fernando Ferrari, 515, Goiabeiras - 29075-910 - Vitória - ES - Brasil

Instituto Federal de Educação, Ciência e Tecnologia do Espírito Santo (IFES) Campus Santa Teresa - ES - Brasil

archimedesdifes.edu.br, lucasbr.dafonseca@gmail.com, \{jpalmeida, falbo\} @inf.ufes.br

\begin{abstract}
Data on government expenditure is predominant in open government portals, attracting the attention of citizens in the control of public expenses. Despite that, there are a number of barriers for consuming government expenditure data by citizens and computational systems. These include the lack of standardization in the structure of data, as well as the significant complexity of the (highly technical and specialized) subject domain. In this paper, we address these problems with a reference ontology for the Brazilian federal public budget (ORDP), integrating the stages from the authorization of budgetary programming to the payment of expenses by public administration bodies. ORDP development was based in a systematic Ontology Engineering method, defining its purpose, scope, requirements and modularization aspects. ORDP is modeled in a well-founded language, and defines axioms to the domain rules. ORDP applicability is demonstrated through a data integration use case about expenses of a federal agency, in which data was extracted from governmental web systems and transparency portals.
\end{abstract}

Keywords. Public Budget; Public Expenditure; Reference Ontology; Conceptual Model; Semantic Integration.

Resumo. Dados de execução da despesa pública são os principais dados disponibilizados pelos portais de informação governamentais e atraem o interesse da sociedade no controle dos gastos públicos. Apesar disso, o consumo e análise desses dados, tanto por sistemas computacionais quanto pelos cidadãos, têm sido dificultados pela falta de padronização na estruturação dos dados, bem como pela alta complexidade do domínio (técnico e especializado). A fim de mitigar esses problemas, propõe-se neste trabalho uma Ontologia de Referência para a autorização orçamentária e execução da Despesa Pública federal (ORDP), integrando os estágios desde a autorização

Cite as: Detoni, A. A., Fonseca, L. B. R., Almeida, J. P. A. \& Falbo, R. A. (2018). A Reference Ontology for Budgetary Authorization and Execution of Public Expenditure (Uma Ontologia de Referência para Autorização Orçamentária e Execução da Despesa Pública). iSys: Revista Brasileira de Sistemas de Informação (Brazilian Journal of Information Systems), 11(3), 04-53. 
da programação orçamentária até o pagamento de despesas pelos órgãos da administração pública. O desenvolvimento de ORDP baseou-se em um método sistemático de Engenharia de Ontologia. Foram definidos propósito, escopo, requisitos e modularização de ORDP. ORDP foi modelada utilizando uma linguagem de representação bem fundamentada, assim como foram definidos axiomas para capturar regras de domínio. A aplicabilidade da ontologia é demonstrada através de seu uso na integração de dados sobre execução da despesa pública do governo federal extraídos do Portal da Transparência e dados sobre autorização orçamentária obtidos de um sistema de informação federal.

Palavras-Chave. Orçamento Público; Despesa Pública; Ontologia de Referência; Modelo Conceitual; Integração Semântica.

\section{Introdução}

O orçamento público surgiu com o objetivo de controlar a arrecadação e os gastos dos governos pelo parlamento. Inspirados na Carta Magna Inglesa de 1215, os orçamentos modernos passaram a ter previsão de receita e despesa anual obrigatória em lei, e a despesa pública passou a ser realizada apenas com autorização legislativa [Giacomoni 2010].

No Brasil, a Lei Orçamentária Anual (LOA) é o instrumento de gestão e de transparência que realiza a previsão e autorização das ações planejadas pelo governo para um exercício financeiro que, comumente, corresponde ao período de $1^{\circ}$ de janeiro a 31 de dezembro do ano seguinte ao da aprovação da lei [Ministério do Planejamento, Desenvolvimento e Gestão 2016]. Dessa forma, os mecanismos de gestão e fiscalização do orçamento federal brasileiro devem abranger tanto a elaboração da lei orçamentária, quanto a execução das despesas públicas em conformidade com o planejamento, permitindo, em princípio, um controle completo do ciclo de vida das despesas desde a sua previsão até o efetivo pagamento de credores.

Considerando o interesse da sociedade no controle dos gastos públicos e no combate à corrupção, não surpreende que os principais dados disponibilizados pelos portais de informações governamentais sejam relativos às despesas públicas. Exemplos incluem o Portal da Transparência do Governo Federal (disponível em http://www.portaltransparencia.gov.br/) e o Portal da Transparência do Estado do Espírito Santo (disponível em http://transparencia.es.gov.br).

Apesar da ampla disponibilização de dados sobre despesas (em atendimento à Lei de Acesso à Informação - Lei n 12.527/2011 e, mais recentemente, à Política de Dados Abertos do Poder Executivo Federal - Decreto $n^{\circ}$ 8.777, de 11/05/2016), a falta de padronização na estruturação dos dados nos portais, bem como as fontes heterogêneas e não integradas das quais eles advêm, dificultam o consumo e análise desses dados tanto pelos cidadãos quanto por sistemas computacionais. No caso específico de dados de orçamento e despesas públicas, há também a barreira da complexidade do domínio (técnico e especializado), amplificada pela falta de uma descrição clara e precisa dos conceitos envolvidos, o que diminui o interesse de quem pretende utilizar os dados disponibilizados pelos órgãos públicos.

Como exemplo dessa falta de padronização e integração dos sistemas governamentais brasileiros, podem ser citados os sistemas computacionais no âmbito 
federal que estão envolvidos nos processos de programação orçamentária e pagamento das despesas públicas: (i) o Sistema Integrado de Planejamento e Orçamento (SIOP) desenvolvido e mantido no âmbito da Secretaria de Orçamento Federal do Ministério do Planejamento, Orçamento e Gestão, para apoiar a elaboração das leis orçamentárias e suas alterações, assim como para acompanhar a execução das ações orçamentárias autorizadas; e (ii) o Sistema Integrado de Administração Financeira (SIAFI) - desenvolvido e administrado pela Secretaria do Tesouro Nacional, do Ministério da Fazenda, e utilizado para registro, acompanhamento e controle da execução orçamentária, financeira e patrimonial do governo federal.

Vale ressaltar que o exemplo anterior trata de dois sistemas desenvolvidos e mantidos no âmbito de diferentes órgãos da administração pública, com o intuito de apoiar processos distintos, mas que precisam de um maior grau de interoperabilidade, a fim de apoiar adequadamente a integração dos processos relativos à autorização do orçamento e à execução da despesa pública. Uma evidência dessa lacuna é a dificuldade em se obter informações que dependam do cruzamento entre os dados do SIOP e SIAFI. Por exemplo, tomando como base uma determinada autorização orçamentária descrita na LOA (dados disponíveis no $\mathrm{SIOP}^{\circledR}$ ): Quais foram os maiores beneficiários, pessoas jurídicas ou físicas, que receberam pagamentos realizados pelo órgão autorizado (dados disponíveis no SIAFI)? Quanto do valor autorizado na LOA (constante no SIOP) foi efetivamente objeto de pagamentos (dados do SIAFI)?

Em síntese, a parte do domínio de orçamento público que envolve desde a autorização orçamentária, até o efetivo pagamento da despesa pública, apresenta problemas, alguns já evidenciados por [Craveiro et al. 2013] e [Fonseca et al. 2016], tais como: (i) complexidade do domínio, envolvendo conceitos, relações e processos incomuns para a maioria dos cidadãos; (ii) carência de padronização na estruturação dos dados publicados; (iii) falta de clareza e precisão semântica na descrição dos conceitos do domínio, que são falhas marcantes desde os regulamentos legais sobre o tema, passando pelos manuais dos sistemas informatizados de apoio, e até mesmo nos glossários dos Portais de Transparência governamentais; (iv) baixo grau de interoperabilidade entre os sistemas de apoio aos processos envolvidos.

Esses problemas configuram caso típico de interoperabilidade semântica, que vem sendo tratado na literatura através da aplicação de abordagens baseadas em ontologias [Charalabidis et al. 2010; Nardi et al. 2013; Scholl \& Klischewski 2007]. O próprio governo federal tem investido na construção de ontologias a fim de possibilitar o intercâmbio de informações no nível semântico, buscando viabilizar a interoperabilidade entre diversas fontes de dados, como aquelas disponibilizadas no portal e-VoG (Repositório de Vocabulários e Ontologias do Governo Eletrônico - disponível em http://vocab.e.gov.br/) e o "Modelo Ontológico da Classificação das Despesas do Orçamento Federal Brasileiro" [Secretaria de Orçamento Federal 2013].

Pesquisando a literatura foram identificados dois trabalhos que apresentam ontologias relacionadas ao domínio de orçamento público, [Araújo et al. 2012] e [Martins et al. 2013]. Contudo, nenhuma delas abrange conceitos integrando as etapas de autorização orçamentária e de execução da despesa pública. Nesse sentido, este artigo

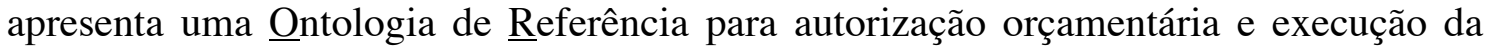

http://www1.siop.planejamento.gov.br/sparql/

iSys: Revista Brasileira de Sistemas de Informação (isys: Brazilian Journal of Information Systems) http://seer.unirio.br/index.php/isys/ 
Despesa Pública (ORDP), que é um modelo de um domínio específico do conhecimento, buscando identificar com maior clareza e precisão a natureza semântica das entidades e suas inter-relações para o domínio de orçamento público, melhorando sua compreensão, assim como viabilizando, no nível semântico, a integração e uso dos dados publicados pelo governo e seu processamento por sistemas computacionais externos ao governo. $\mathrm{O}$ escopo da ontologia proposta abrange os conceitos centrais inerentes ao domínio de autorização orçamentária e execução da despesa pública federal, contemplando desde a programação estabelecida na LOA até o efetivo pagamento da despesa.

O desenvolvimento da ontologia baseou-se no método SABiO (Systematic Approach for Building Ontologies) [Falbo 2014], por ser um método de engenharia de ontologia consolidado, o qual provê um conjunto de atividades e diretrizes claras para o desenvolvimento de ontologias. Além disso, neste trabalho mostrou-se importante o suporte do método $\mathrm{SABiO}$, cujo processo de desenvolvimento prescreve desde a identificação dos aspectos iniciais para concepção de uma ontologia de referência, até as etapas de implementação e testes de uma versão operacional dessa ontologia.

A formalização de ORDP utilizou um perfil UML bem fundamentada, OntoUML [Guizzardi 2005], o qual utiliza meta-propriedades ontológicas e a categorização de objetos propostas em UFO (Unified Foundational Ontology), permitindo a criação de ontologias consistentes.

ORDP é avaliada de duas formas: (i) demonstrando como os conceitos, relações e axiomas formalizados na descrição da ontologia de referência são capazes de atender aos requisitos previamente definidos, os quais são descritos por meio de questões de competência (QCs); e (ii) realizando uma prova de conceito a partir do desenvolvimento de aplicações que utilizam uma versão operacional da ontologia para integrar dados reais sobre execução da despesa pública do governo federal e dados sobre autorização orçamentária, os quais foram extraídos, respectivamente, do Portal da Transparência (originários do SIAFI) e do SIOP, utilizando tecnologias da Web Semântica.

O restante deste artigo está organizado da seguinte forma: na Seção 2 são apresentados os conceitos básicos sobre orçamento público, destacando-se a execução da despesa pública; a Seção 3 apresenta o referencial teórico para este trabalho; a Seção 4 apresenta a ontologia de referência sobre autorização orçamentária e execução da despesa pública com foco na aquisição de bens e materiais; a Seção 5 apresenta uma iniciativa de integração de dados governamentais usando a ontologia de referência proposta; por fim, nas Seções 6 e 7 são apresentados, respectivamente, os trabalhos relacionados e conclusões.

\section{Orçamento Público - Autorização Orçamentária e Execução da Despesa}

O orçamento público é o "instrumento pelo qual o governo estima as receitas e fixa as despesas para poder controlar as finanças públicas e executar as ações governamentais, ensejando o objetivo estatal do bem comum" [Ministério do Planejamento Desenvolvimento e Gestão 2016]. Portanto, é por meio do orçamento público que a administração pública assume o compromisso de entregar à sociedade um conjunto de produtos e serviços, assim como, prevê a arrecadação que espera receber dessa mesma sociedade. Dessa forma, o mecanismo orçamentário tende a induzir o gestor público a agir com responsabilidade no uso dos recursos públicos e permite à sociedade auxiliar no 
controle das ações desses gestores, checando se os recursos estão sendo usados adequadamente.

$\mathrm{O}$ art. 165 da Constituição Federal de 1988 em conjunto com a lei 4.320/64 estabelecem um processo para o orçamento federal brasileiro, ou seja, um processo orçamentário, que compreende duas etapas principais, a saber, a autorização orçamentária e a execução orçamentária. Vale lembrar que o escopo deste trabalho se ocupa exclusivamente dos aspectos inerentes à autorização e execução das despesas públicas, não contemplando aspectos sobre as receitas.

\subsection{Etapa de Autorização Orçamentária}

A etapa de autorização orçamentária compreende o planejamento das ações de governo por meio da elaboração e aprovação de três leis ordinárias que autorizam as ações governamentais, a saber, o Plano Plurianual (PPA), a Lei de Diretrizes Orçamentárias (LDO) e a Lei Orçamentária Anual (LOA);

O PPA tem vigência de quatro anos. Nele são estabelecidas as políticas de médio prazo a serem cumpridas pela administração pública. Dessa forma, o PPA orienta a atuação governamental por meio de programas temáticos (entrega de bens e serviços à sociedade) e programas de gestão, manutenção e serviços (apoio à gestão e manutenção da ação governamental), com suas respectivas diretrizes, objetivos e metas. A LDO, de vigência anual, enuncia as políticas públicas e respectivas prioridades para o exercício seguinte. A LOA estima as receitas e fixa a programação das despesas para o exercício financeiro. Dessa forma, a LDO serve como intermediadora entre o PPA (plano de médio prazo do governo) e a LOA, identificando no PPA os programas que receberão prioridade no exercício seguinte e que deverão ser implementados através das ações previstas na LOA, durante o exercício a que se refere [Senado Federal 2016].

A Figura 1 apresenta um fragmento da LOA de 2016 [Câmara dos Deputados 2016], mostrando como os créditos orçamentários são alocados para os diversos órgãos que compõem a administração pública. Para cada órgão está prevista uma série de Ações Governamentais que são vinculadas ao contexto de um Programa Governamental, para as quais são fixadas suas respectivas dotações orçamentárias, ou seja, um limite de crédito que pode ser comprometido com as despesas decorrentes de cada ação autorizada.

\begin{tabular}{|c|c|c|c|c|c|c|c|c|c|}
\hline $\begin{array}{l}\text { Órgão: } \\
\text { Unidade: } \\
\text { Quadro dos Crédi }\end{array}$ & $\begin{array}{l}26000 \text { Ministério da Educação } \\
26406 \text { Instituto Federal do Espírito } \\
\text { tos Orçamentários }\end{array}$ & to & & & & & & & \\
\hline Programática & Programa/Ação/Localização & Funcional & Esf & $G N D$ & $R P$ & Mod & $I U$ & Fte & Valor \\
\hline 2080 & Educação de qualidade para todos & & & & & & & & 94.639 .043 \\
\hline & Atividades & & & & & & & & 94.639 .043 \\
\hline 2080.2994 & $\begin{array}{l}\text { Assistência ao Estudante da Educação } \\
\text { Profissional e Tecnológica }\end{array}$ & & & & & & & & 15.686 .701 \\
\hline 2080.2994 .0032 & $\begin{array}{l}\text { Assistência ao Estudante da Educação } \\
\text { Profissional e Tecnológica - No Estado do } \\
\text { Espírito Santo } \\
\quad \text { - Benefício Concedido (unidade): } 85.000\end{array}$ & 12.363 & $\mathrm{~F}$ & $3-\mathrm{ODC}$ & 2 & 90 & 0 & 100 & $\begin{array}{r}\mathbf{1 5 . 6 8 6 . 7 0 1} \\
15.686 .701\end{array}$ \\
\hline
\end{tabular}

Figura 1. Exemplo de Autorização Orçamentária da LOA 2016 (extraído de [Câmara dos Deputados 2016])

Tendo sido explicada a etapa de autorização orçamentária da despesa pública, é importante notar que o orçamento público é composto por um grande volume de 
autorizações de despesas (com tendência de crescimento a cada ano) e, portanto, faz-se necessário o uso de critérios de classificação que permitam uma melhor organização e recuperação das informações sobre essas despesas [Giacomoni 2010]. Historicamente, a administração pública tem buscado formular critérios de classificação para a estrutura orçamentária, objetivando aumentar a transparência e facilitar o controle e a fiscalização do gasto público [Araújo et al.2012].

Dessa forma, a classificação das despesas públicas é o mecanismo pelo qual se faz o agrupamento das despesas por classificadores. Por este meio é possível, por exemplo, organizar o orçamento por Poder (Quem é o responsável pela despesa?), por função e subfunção de governo (Em que áreas do governo - saúde, educação, segurança - a ação será realizada?), por programa (Qual o tema da política pública? Por exemplo, "Educação de Qualidade para Todos") e por categoria econômica (Trata-se de despesa com custeio ou investimento em bens de capital?) [Senado Federal 2016].

Portanto, para compreender, consultar, acompanhar e fiscalizar o processo orçamentário é fundamental dominar seu sistema de classificação a fim de estabelecer as relações entre as ações da administração pública e os valores financeiros associados (e.g. gasto em quê, para quê, sob a responsabilidade de quem) [Araújo et al. 2012].

O modelo brasileiro contempla os seguintes critérios de classificação das autorizações orçamentárias, conforme ilustrado na Figura 2: (i) esfera; (ii) institucional; (iii) funcional; (iv) estrutura programática; e (v) natureza da despesa [Ministério do Planejamento Desenvolvimento e Gestão 2016].

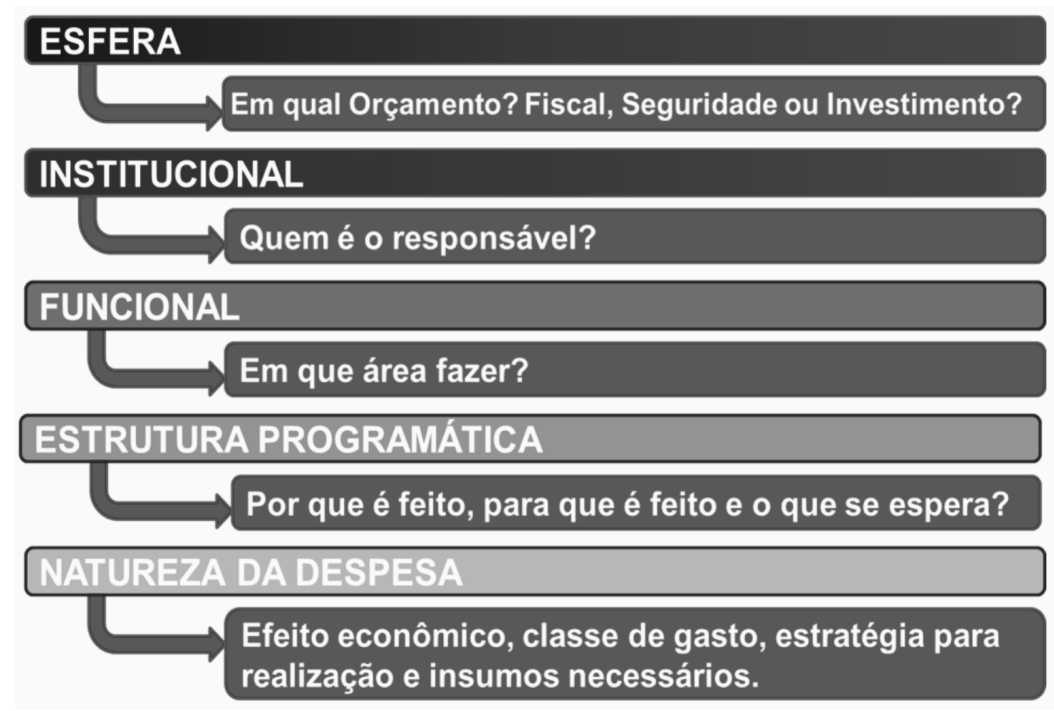

Figura 2. Critérios de Classificação das Despesas Públicas

Além disso, as autorizações previstas na LOA recebem um identificador numérico que é estruturado de acordo com cada um desses critérios de classificação das autorizações de despesa, seguindo o exemplo apresentado na Figura 3.

A classificação por esfera orçamentária tem por finalidade identificar se a autorização de despesa pertence ao Orçamento Fiscal (letra "F" no texto da LOA ou código 10 na base de dados do SIOP), da Seguridade Social (letra "S" ou código 20) ou de Investimento das Empresas Estatais (letra "I" ou código 30) [Ministério do Planejamento Desenvolvimento e Gestão 2016]. 
A classificação institucional identifica a unidade organizacional pública responsável pela realização da ação orçamentária, compreendendo dois níveis hierárquicos: (i) órgão (dois primeiros dígitos do identificador da classificação institucional) - corresponde às unidades administrativas de maior nível hierárquico que agrupam unidades orçamentárias; (ii) unidade orçamentária (UO) (três últimos dígitos do identificador da classificação institucional) - unidades de menor nível hierárquico, que são responsáveis pela execução da despesa [Ministério do Planejamento, Desenvolvimento e Gestão 2016]. No exemplo da Figura 3, o órgão indicado é o Ministério da Educação (identificador 26) e a UO é o Instituto Federal do Espírito Santo (identificador 406).

\begin{tabular}{|c|c|c|c|c|c|c|c|c|c|}
\hline & CÓDIGO & 10. & 26. & 406. & 12. & 363. & 2080. & 2994. & 0032. \\
\hline & ra: Orçamento Fiscal & 10 & & & & & & & \\
\hline CIASSIFICACÃO & Órgão: Ministério da Educação & & 26 & & & & & & \\
\hline INSTITUCIONAL & $\begin{array}{c}\text { Unidade Orçamentária: Instituto } \\
\text { Federal do Espírito Santo }\end{array}$ & & & 406 & & & & & \\
\hline CLASSIFICACÃO & Função: Educação & & & & 12 & & & & \\
\hline FUNCIONAL & Subfunção: Ensino Profissional & & & & & 363 & & & \\
\hline & $\begin{array}{l}\text { Programa: Educação de Qualidade } \\
\text { para Todos }\end{array}$ & & & & & & 2080 & & \\
\hline $\begin{array}{l}\text { CLASSIFICAÇÃO } \\
\text { PROGRAMÁTICA }\end{array}$ & $\begin{array}{l}\text { Ação: Assistência ao Estudante da } \\
\text { Educação Profissional e Tecnológica }\end{array}$ & & & & & & & 2994 & \\
\hline & $\begin{array}{c}\text { Subtítulo (Localização): No Estado } \\
\text { do Espírito Santo }\end{array}$ & & & & & & & & 32 \\
\hline
\end{tabular}

Figura 3. Exemplo de Código Numérico da Classificação da Autorização Orçamentária (adaptada de [Ministério do Planejamento, Desenvolvimento e Gestão 2016])

A classificação funcional indica em qual área a ação governamental será realizada (p. ex., legislativa, judiciária, segurança pública, saúde, educação etc.), sendo formada por dois campos: (i) função, cujo identificador possui dois dígitos - p. ex., função 12 Educação; (ii) subfunção, cujo identificador possui três dígitos - p. ex., subfunção 363 Ensino Profissional. Vale destacar que se trata de uma classificação independente da institucional e da programática. Por exemplo, pode haver uma ação classificada na função 09 - Assistência Social sendo realizada pelo órgão Ministério da Educação. Além disso, as subfunções podem ser combinadas com funções diferentes daquelas a que estejam vinculadas precipuamente [Ministério do Planejamento, Desenvolvimento e Gestão 2016].

A classificação programática baseia-se na estruturação das ações organizadas a partir dos programas de governo definidos no PPA. Assim, conforme ilustrado na Figura 4, para cada Programa (planejado no PPA e com execução através de ações previstas na LOA), são identificadas as Ações (projetos, atividades ou operações especiais) e especificados os respectivos valores e metas, a fim de solucionar um problema ou atender uma demanda da sociedade. Nesta categoria de classificação também é identificado o subtítulo (localizador do gasto, p. ex. 0032 - No Estado do Espírito Santo ou 0010 - Na Região Norte) [Ministério do Planejamento, Desenvolvimento e Gestão 2016].

Cada programa é identificado por um código de quatro dígitos. Retomando o exemplo da Figura 3, o programa "Educação de qualidade para todos" possui o identificador 2080. As ações, por sua vez, são identificadas por um código alfanumérico 
de oito dígitos, onde o primeiro dígito do código identifica se a ação é um projeto (dígitos 1, 3, 5 ou 7), uma atividade (dígitos 2, 4, 6 ou 8), ou uma operação especial (dígito 0); os três dígitos seguintes identificam uma ação específica; e os quatro últimos dígitos identificam o subtítulo (localizador) da ação. O exemplo da Figura 3 traz a ação "Assistência ao Estudante da Educação Profissional e Tecnológica" cujo código é 2994 (o primeiro dígito " 2 " indica que se trata de uma atividade). Os últimos quatro dígitos, 0032 identificam o subtítulo (localização) "No Estado do Espírito Santo".

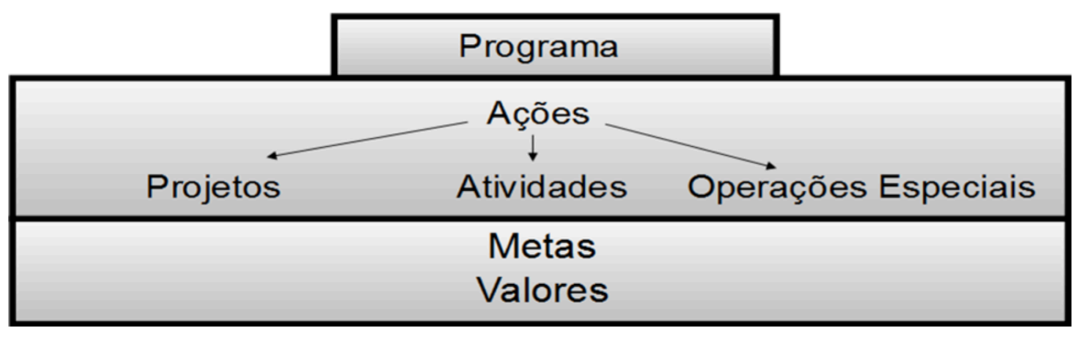

Figura 4. Programas e Ações para Organização das Despesas no Orçamento Público

A classificação por natureza de despesa possibilita obter tanto informação macroeconômica sobre o efeito do gasto do setor público na economia (categoria econômica, grupo de natureza e modalidade de aplicação), quanto para controle gerencial do gasto (elemento da despesa) [Ministério do Planejamento Desenvolvimento e Gestão 2016][Tesouro Nacional 2016a], conforme detalhado a seguir:

(i) Categoria econômica: indica os efeitos da ação sobre a economia do país, podendo ser uma "Despesa Corrente" (código 3, como ocorre no caso do exemplo da Figura 1) ou uma "Despesa de Capital" (código 4);

(ii) Grupo de natureza da despesa (GND): subdivide as categorias econômicas conforme mostrado na Tabela 1, servindo ainda como agregador dos elementos de despesa com as mesmas características quanto ao objeto do gasto público (seu identificador é formado por um dígito no SIOP) [Ministério do Planejamento, Desenvolvimento e Gestão 2016]. Retomando o exemplo da Figura 1, verifica-se que o GND daquela ação é "ODC" (Outras Despesas Correntes);

(iii) Modalidade de aplicação: indica se os recursos são aplicados diretamente por órgão ou entidade no âmbito do mesmo nível de Governo, ou por outro ente da Federação. É identificado por um código de dois dígitos, como no exemplo da Figura 1, em que a coluna "Mod" apresenta o valor "90 - Aplicações Diretas" (outros exemplos de valores seriam "20 - Transferências à União"; "30 - Transferências a Estados e ao Distrito Federal").

Tabela 1. Quadro de Categorias Econômicas e Grupos de Natureza de Despesa

\begin{tabular}{|l|l|}
\hline Categorias Econômicas & Grupos de Natureza da Despesa \\
\hline \multirow{3}{*}{3 - Despesa Corrente } & 1 - Pessoal e Encargos Sociais \\
\cline { 2 - 2 } & 2 - Juros e Encargos da Dívida \\
\cline { 2 - 2 } & 3 - Outras Despesas Correntes \\
\hline \multirow{3}{*}{4 - Despesa de Capital } & 4 - Investimentos \\
\cline { 2 - 2 } & 5 - Inversões financeiras \\
\cline { 2 - 2 } & 6 - Amortização da Dívida \\
\hline
\end{tabular}




\subsection{Etapa de Execução da Despesa}

Uma vez que as autorizações de despesas fixadas na LOA, foram devidamente aprovadas, inicia-se a etapa de execução orçamentária, ou mais especificamente, a etapa de execução da despesa pública (respeitando o escopo deste trabalho). Esta etapa é subdividida em três estágios, conforme previsto na lei 4.320/64: Empenho, Liquidação e Pagamento.

O empenho pode ser realizado uma vez que sejam atendidos os condicionantes, a saber: autorização orçamentária através da LOA, disponibilidade financeira e realização de processo licitatório, quando aplicável. Ele faz parte, geralmente, da contratação, por um órgão público, da aquisição de um bem material ou de serviço, autorizando a reserva de dotação orçamentária para um fim específico, funcionando como garantia ao credor do ente público de que existe o crédito orçamentário necessário para a liquidação de um compromisso assumido. O documento usado para registrar um empenho é a Nota de Empenho [Tesouro Nacional 2016b].

Após devidamente empenhada, a despesa pública passa para o estágio de liquidação, em que é verificado objetivamente o cumprimento do contrato pelo credor. Ou seja, neste estágio o ente público fiscaliza se a entrega dos materiais/bens, a prestação dos serviços ou a obra foi realizada adequadamente pelo credor, evitando, dessa forma, o pagamento sem cumprimento prévio das condições, quando forem exigidas. O documento gerado na liquidação é a Nota de Lançamento ou Nota de Sistema [Tesouro Nacional 2016b].

O pagamento, último estágio da execução da despesa, extingue a obrigação do ente público com o credor, consistindo no efetivo repasse de numerário ao último. Esse procedimento é efetuado comumente através de crédito em conta bancária, registrado em Ordem Bancária que tenha como favorecido o credor do empenho [Tesouro Nacional 2016b].

Retomando o sistema de classificação das despesas públicas, vale destacar que o modelo brasileiro apresenta ainda uma parte do critério de classificação por natureza de despesa que não pode ser identificada na etapa de autorização orçamentária (portanto, não é informada na LOA), mas apenas a partir da etapa de execução da despesa (a partir do estágio de empenho da despesa), e por esse motivo não está presente no exemplo da Figura 1. Trata-se da classificação por elemento e subelemento de despesa, que tem a finalidade de identificar o objeto imediato de cada despesa. Seu código é formado por quatro dígitos (dois primeiros dígitos para identificar o elemento, e os dois últimos para o subelemento), como por exemplo: o elemento "30 - Material de Consumo" e o subelemento "07 - Gêneros de Alimentação"; ou o elemento "32 - Material, Bem ou Serviço para Distribuição Gratuita" e o subelemento "04 - Material Educacional e Cultural".

\section{Referencial Teórico}

Na seção anterior, além da contextualização sobre o domínio de orçamento público envolvendo a autorização orçamentária e a execução da despesa pública, buscou-se mostrar a complexidade inerente ao domínio, envolvendo conceitos, relações e processos específicos, incomuns para a maioria dos cidadãos, e que podem ser mais precisamente definidos por meio de uma ontologia de referência, visando estabelecer uma conceituação explícita e compartilhada acerca do mesmo. Nesta seção, são apresentados o referencial 
teórico relativo a ontologias e os métodos e técnicas usados na construção da ontologia apresentada neste artigo, e que viabilizam a iniciativa de integração semântica das bases de dados relatada na Seção 5.

\subsection{Ontologias}

Uma ontologia é uma especificação parcial, formal e explícita de uma conceituação compartilhada [Guarino et al. 2009]. O termo conceituação refere-se a um conjunto de conceitos e relações relevantes para articular sobre um fenômeno do mundo real. Parcial diz respeito ao fato de apenas certos aspectos da realidade serem alvo de uma ontologia. Explícita significa que os conceitos usados e as restrições sobre seu uso são definidos explicitamente. Formal refere-se ao nível de expressividade da linguagem usada para descrever a ontologia. Linguagens lógicas são normalmente consideradas formais. Compartilhada reflete o fato de uma ontologia capturar o conhecimento consensual aceito por uma comunidade.

Uma importante distinção entre ontologias como modelos conceituais é feita por [Guizzardi 2007], conhecidas como ontologias de referência, e ontologias como artefatos de codificação, chamadas de ontologias operacionais. Uma ontologia de referência é construída com o objetivo de fazer a melhor descrição possível do domínio na realidade. É um tipo especial de modelo conceitual, um artefato de engenharia com o requisito adicional de representar um modelo de consenso (ou modelo de referência) dentro de uma comunidade. Por outro lado, uma vez que os usuários já tenham acordado uma concepção comum, as versões operacionais de uma ontologia de referência podem ser criadas. Ao contrário das ontologias de referência, ontologias operacionais são projetadas com o foco na garantia de propriedades computacionais desejáveis [Falbo et al. 2013].

\subsection{Abordagem de Engenharia de Ontologias}

Como suporte para o desenvolvimento da ontologia de referência, foi utilizada a abordagem de engenharia de ontologias SABiO (Systematic Approach for Building Ontologies) proposta em [Falbo 2014]. A abordagem é focada no desenvolvimento de ontologias de domínio (referência e operacional) e possui um processo de desenvolvimento composto de cinco fases, conforme ilustrado na Figura 5:

(i) Identificação de Propósito e Definição de Requisitos: Inicialmente, os propósitos e usos pretendidos para a ontologia devem ser identificados. Com os propósitos definidos, passa-se ao levantamento de requisitos, por meio de questões de competência (QCs - questões que a ontologia deve responder) e à modularização da ontologia (divisão da ontologia em subontologias a fim de lidar com sua complexidade).

(ii) Captura e Formalização da Ontologia: Etapa de modelagem conceitual usando linguagens de representação adequadas e definição de axiomas (formais e informais).

(iii) Design: Etapa de refinamento da ontologia, levando em conta aspectos computacionais (p. ex.: desempenho do raciocínio).

(iv) Implementação: Codificação na linguagem operacional escolhida (p. ex.: OWL).

(v) Testes: SABiO propõe uma abordagem de testes dirigidos por questões de competência, na qual as questões são implementadas por meio de consultas (queries) na linguagem da ontologia operacional, buscando-se obter o resultado esperado. 
Ainda que o processo de desenvolvimento proposto sugira uma sequência na realização de suas atividades, $\mathrm{SABiO}$ não prescreve um modelo de ciclo de vida específico. Ao contrário, qualquer modelo de ciclo de vida pode ser usado. Além disso, paralelamente às atividades do processo de desenvolvimento, são realizadas atividades de processos de apoio, a saber: Aquisição de Conhecimento, Documentação, Gerência de Configuração, Avaliação e Reutilização.

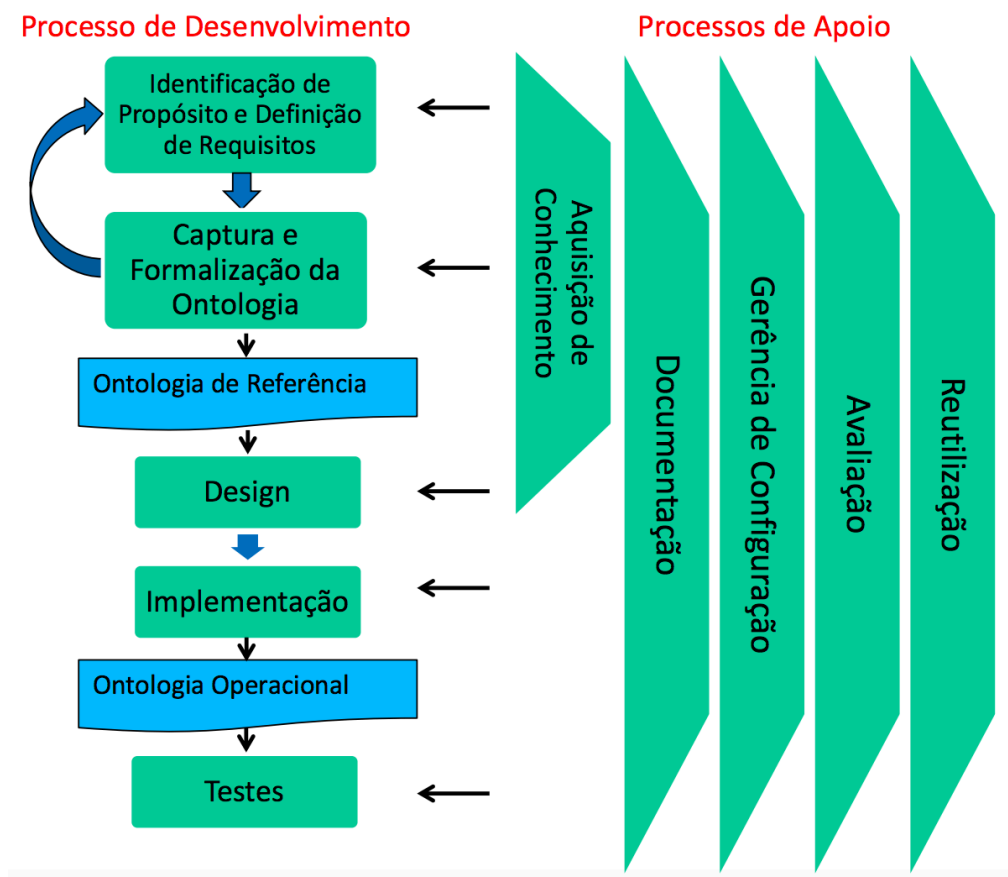

Figura 5. Método SABiO para desenvolvimento de ontologias (adaptada de
[Falbo 2014])

\subsection{Abordagem de Representação}

Para representar a ontologia de referência sobre Autorização Orçamentária e Execução de Despesa Pública Federal, foi utilizada a linguagem OntoUML [Guizzardi 2005], uma versão ontologicamente bem fundamentada da UML 2.0, que introduz estereótipos no diagrama de classes com base em meta-propriedades ontológicas, as quais permitem a criação de ontologias consistentes e alinhadas com a Ontologia de Fundamentação Unificada (Unified Foundational Ontology - UFO). A Tabela 2 apresenta os estereótipos de OntoUML que são usados neste artigo.

Tabela 2. Subconjunto dos Estereótipos de OntoUML

\begin{tabular}{|c|l|}
\hline Estereótipo & \multicolumn{1}{|c|}{ Principal Característica } \\
\hline «kind» & $\begin{array}{l}\text { Tipos rígidos }{ }^{2} \text { que fornecem princípio de identidade para suas } \\
\text { instâncias (p. ex., Pessoa, Órgão) }\end{array}$ \\
\hline «subkind» & $\begin{array}{l}\text { Tipos rígidos cujas instâncias especializam instâncias de um «kind» }(\mathrm{p} . \\
\text { ex., Homem, Mulher) }\end{array}$ \\
\hline
\end{tabular}

¿Um tipo T é rígido se para toda instância x de T, x é necessariamente uma instância de T (no senso modal). Em outras palavras, se $\mathrm{x}$ instancia $\mathrm{T}$ em um dado mundo w, então $\mathrm{x}$ deve instanciar $\mathrm{T}$ em todo mundo possível w'.

iSys: Revista Brasileira de Sistemas de Informação (isys: Brazilian Journal of Information Systems) http://seer.unirio.br/index.php/isys/ 
Tabela 2. Subconjunto dos Estereótipos de OntoUML (continuação)

\begin{tabular}{|c|c|}
\hline Estereótipo & Principal Característica \\
\hline «category» & $\begin{array}{l}\text { Tipos rígidos que capturam propriedades comuns, ou compartilhadas, } \\
\text { entre entidades que possuem diferentes princípios de identidade (p. ex. } \\
\text { a categoria Entidade Racional, como uma generalização de Pessoa e } \\
\text { Agente Inteligente) }\end{array}$ \\
\hline «role» & $\begin{array}{l}\text { Tipos anti-rígidos }{ }^{3} \text { instanciados no escopo de uma relação (p. ex., } \\
\text { Estudante, Cônjuge) }\end{array}$ \\
\hline «roleMixin» & $\begin{array}{l}\text { Tipos anti-rígidos que subsumem roles com diferentes critérios de } \\
\text { identidade (p. ex., Cliente - quando aplicado tanto a pessoas físicas } \\
\text { quanto jurídicas) }\end{array}$ \\
\hline «collective» & $\begin{array}{l}\text { Tipos rígidos cujas instâncias são coleções com características em } \\
\text { comum (p. ex., Grupo de Trabalho, agregando pessoas) }\end{array}$ \\
\hline «relator» & $\begin{array}{l}\text { Tipo que reifica uma relação e cujas instâncias são dependentes } \\
\text { existencialmente das entidades relacionadas (p. ex., Casamento, } \\
\text { relacionando pessoas no papel de Cônjuges) }\end{array}$ \\
\hline «mediation» & $\begin{array}{l}\text { Relações formais existentes entre um relator e os tipos relacionados } \\
\text { através daquele relator (p. ex., relação mediation entre um relator } \\
\text { Casamento e um role Cônjuge). Ou seja, como os relators são tipos } \\
\text { existencialmente dependentes das entidades relacionadas por } \\
\text { intermédio deles, os mesmos precisam estar conectados via relações } \\
\text { mediation com aquelas entidades relacionadas. }\end{array}$ \\
\hline
\end{tabular}

Uma importante característica de OntoUML explorada na ontologia apresentada neste artigo é a reificação de relações usando-se o conceito de relator [Guarino e Guizzardi 2015]. Um relator captura a forma como entidades se relacionam em certo contexto, desempenhando papéis (roles) neste contexto. Relators são particularmente importantes para a representação de relações sociais (p. ex., um casamento civil entre duas pessoas, que desempenham os papéis de cônjuges nessa relação). A noção de relator tem sido explorada em trabalhos recentes como conceito chave para a representação de relações legais (UFO-L) [Griffo et al. 2015], relações de serviço (UFO-S) [Nardi et al. 2015] e compromissos sociais (claims/commitments) entre agentes [Guizzardi et al. 2008].

Além de OntoUML, a ontologia de referência também faz uso de MLT (MultiLevel Theory) como suporte à modelagem conceitual multi-nível. MLT foi proposta como uma teoria axiomática formal [Carvalho e Almeida 2016] e tem sido usada para melhorar o suporte ao padrão powertype [Carvalho et al. 2016] em UML, para detectar problemas em taxonomias multi-nível na Web [Brasileiro et al.2016] e para fornecer fundamentação conceitual no desenvolvimento de ontologias que necessitam tratar de tipos em diferentes níveis (p. ex. tipos cujas instâncias são outros tipos, e não indivíduos) [Carvalho et al. 2015]. MLT permite a reificação de classes/tipos, admitindo, assim, a modelagem de

\footnotetext{
Um tipo T é anti-rígido se para toda instância x de T, existe a possibilidade de x não ser uma instância de T. Em outras palavras, se $\mathrm{x}$ instancia $\mathrm{T}$ em um dado mundo w, então existe um mundo possível $\mathrm{w}^{\prime}$ em que $\mathrm{x}$ não instancia $\mathrm{T}$.

iSys: Revista Brasileira de Sistemas de Informação (iSys: Brazilian Journal of Information Systems) http://seer.unirio.br/index.php/isys/
} 
domínios em que o próprio esquema de classificação é parte do domínio a ser representado. No domínio em questão, há diversos tipos de despesa orçamentária a serem considerados. Esses tipos têm relações entre si, assim como são objeto de prescrição no escopo da LOA, justificando, portanto, o uso de uma teoria para modelagem multi-nível como MLT. No escopo deste artigo, tipos cujas instâncias são outros tipos são representados com o estereótipo $<<2$ ndOT $>>$ (uma abreviação de "second-order types").

A partir do modelo conceitual capturado na ontologia de referência, foram utilizadas tecnologias da Web Semântica para implementar a ontologia operacional. Segundo [Berners-Lee et al. 2001], os dados na Web Semântica devem ser interligados por meio de relações nomeadas, atribuindo um significado (sentido) ao seu conteúdo, e expondo-os na Web de forma que tanto pessoas quanto computadores consigam interpretá-los. Na maioria das vezes, o conteúdo na Web Semântica tem sido representado na linguagem OWL (Web Ontology Language), uma extensão de RDF (framework para representar informações estruturadas em triplas na Web) desenvolvida pelo $\mathrm{W}^{3} \mathrm{C}^{4}$ que provê recursos adicionais de expressividade para descrição de tipos e propriedades [McGuinness e Harmelen 2004]. A representação de dados em OWL é feita por meio de um conjunto de triplas, onde cada tripla é composta de um sujeito, um predicado e um objeto (p. ex. "Pedro" - "conhece" - "Paulo") [Schreiber e Yves 2014]. Dessa forma, os dados OWL precisam ser armazenados em banco de dados de triplas, chamados de triplestores, e podem ser consultados por meio da linguagem SPARQL (Simple Protocol and RDF Query Language) [Harris e Seaborne 2013] (uma linguagem semelhante ao SQL, usada para consultar triplas).

\section{ORDP: Uma Ontologia de Referência para Autorização Orçamentária e Execução da Despesa Pública}

Conforme citado anteriormente, para o desenvolvimento da Ontologia de Referência para Autorização Orçamentária e Execução da Despesa Pública (ORDP) foi adotado o método $\mathrm{SABiO}$. Segundo esse método, a primeira etapa do processo de desenvolvimento de uma ontologia consiste em definir o seu propósito. O propósito de ORDP é: prover um modelo de referência que possa ser usado como base para iniciativas de integração semântica de dados de autorização orçamentária e de execução de despesas públicas.

O escopo da ontologia proposta abrange os conceitos centrais inerentes às seguintes etapas do orçamento público: (i) autorização e gerenciamento orçamentários (a partir da elaboração e aprovação da LOA); e (ii) execução da despesa pública (subdividida nos estágios de empenho, liquidação e pagamento). Contudo, por se tratar de um domínio muito amplo, alguns aspectos não são contemplados neste trabalho, a saber: (i) conceitos sobre a classificação programática da despesa pública (programas de governo e ações orçamentárias), por carecerem de investigação e detalhamento a parte, no domínio envolvendo as conceituações do Plano Plurianual (PPA) e da Lei de Diretrizes Orçamentárias (LDO); (ii) aspectos inerentes à classificação funcional do gasto público; e (iii) execução de despesas públicas que não sejam com aquisição de material de consumo, material permanente, equipamento ou bem patrimonial (p. ex. contratação de

\footnotetext{
-World Wide Web Consortium - comunidade internacional que desenvolve padrões abertos para a Web (https://www.w3.org).
} 
serviços, aposentadorias e pensões, auxílios financeiros, indenizações, subvenções, correções, juros etc.).

Definido o escopo da ontologia, passou-se a identificar as QCs. Essas questões têm como objetivo refinar o escopo da ontologia e guiar o seu desenvolvimento, servindo como documentação de apoio. Além disso, elas também são empregadas como base para a avaliação da qualidade da ontologia de referência, uma vez que se espera que os conceitos e relações presentes na ontologia sejam usados para responder a essas perguntas. As QCs são usadas na versão operacional da ontologia para derivação de consultas que podem ser executadas nos dados estruturados em conformidade com a ontologia operacional, bem como para o projeto de casos de teste.

As seguintes QCs foram identificadas com relação a aspectos da lei orçamentária e das autorizações nela constantes:

QC1. Quais despesas uma organização pública está autorizada a realizar de acordo com a LOA?

QC2. Quais classificadores estão prescritos por uma determinada autorização de despesa?

QC3. Que ente federativo cria uma LOA e, portanto, concede autorizações de despesa nos orçamentos descritos por essa LOA?

QC4. Que tipos de orçamentos podem ser descritos em uma LOA?

As seguintes QCs foram identificadas com relação à etapa de empenho da execução da despesa pública previamente autorizada:

QC5. Quais empenhos foram feitos tendo como base uma determinada autorização de despesa?

QC6. Qual é a unidade gestora e o credor de um empenho?

QC7. Quais itens, relativos a materiais de consumo ou bens, foram empenhados em determinado empenho e quais foram as quantidades e valores associados a cada um dos itens?

QC8. Como é classificado um material descrito em um determinado item de empenho?

QC9. Quais são os classificadores dos itens que compõem um determinado empenho?

QC10. Quais unidades gestoras empenharam recursos de uma determinada autorização de despesa?

QC11. Quais credores foram favorecidos com empenhos relacionados a uma determinada autorização de despesa?

QC12. Em um exercício fiscal, quanto foi empenhado a determinado credor?

QC13. Em um exercício fiscal, qual valor empenhado para determinado classificador de despesa?

QC14. Em um exercício fiscal, qual o valor empenhado por uma determinada unidade gestora?

As seguintes QCs foram identificadas com relação à etapa de liquidação da execução da despesa pública previamente empenhada:

QC15. Qual é a unidade gestora e o credor de uma liquidação? 
QC16. Quais os itens, relativos a materiais de consumo ou bens, foram liquidados em determinada liquidação e quais foram os valores associados a cada um dos itens?

QC17. A quais empenhos se referem uma liquidação e seus itens?

QC18. Quais os materiais liquidados por um item de liquidação?

QC19. Quais liquidações foram feitas tendo como base uma determinada autorização de despesa?

QC20. Em um exercício fiscal, quanto foi liquidado a um determinado credor?

QC21. Em um exercício fiscal, qual valor liquidado para determinado classificador de despesa?

QC22. Em um exercício fiscal, quanto foi liquidado por uma determinada unidade gestora?

As seguintes QCs foram identificadas com relação à etapa de pagamento da execução da despesa pública previamente liquidada:

QC23. Qual é a unidade gestora que realizou um pagamento e qual o credor favorecido por esse pagamento?

QC24. De quais liquidações um pagamento depende?

QC25. A que empenho se refere um item de pagamento?

QC26. Quais pagamentos foram feitos tendo como base uma determinada autorização de despesa?

QC27. Quanto do valor de uma determinada autorização de despesa foi efetivamente objeto de pagamentos?

QC28. Em um exercício fiscal, quanto foi pago a determinado credor?

QC29. Em um exercício fiscal, quanto foi pago por determinada unidade gestora?

QC30.Em um exercício fiscal, qual foi o valor total pago para determinado classificador da despesa?

Com essas questões respondidas, é possível rastrear despesas executadas (ou mais especificamente empenhadas, liquidadas e pagas) em conformidade com a lei orçamentária que autoriza essas despesas, estabelecendo neste processo os papéis das entidades envolvidas e as relações entre elas. Cada uma dessas etapas é detalhada a seguir, apresentando os fragmentos correspondentes da ontologia. 


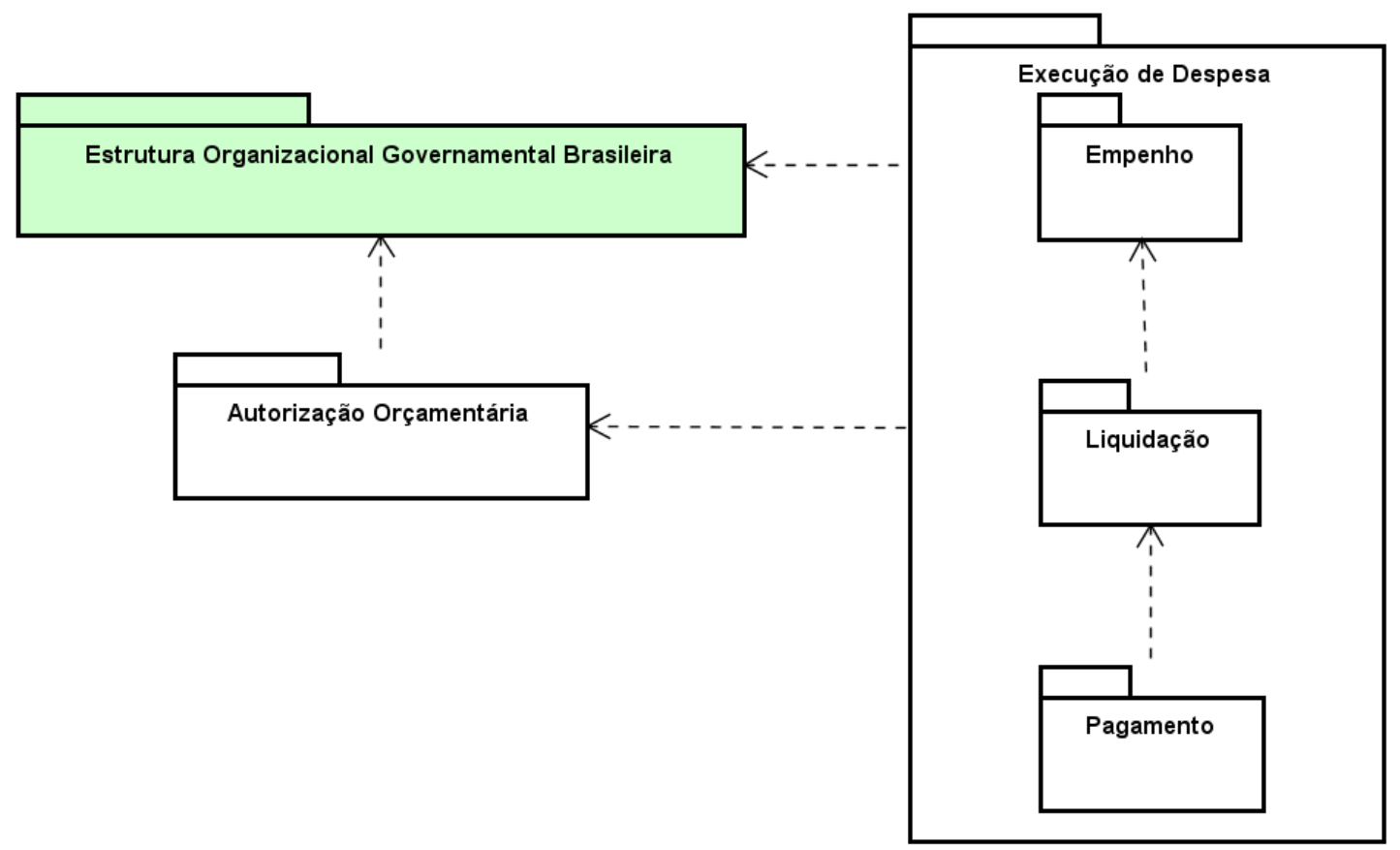

Figura 6. Modularização da ontologia

A Figura 6 apresenta a modularização da ontologia de referência, indicando as subontologias, suas respectivas relações de dependência e, também, explicitando as etapas de autorização orçamentária e de execução da despesa. Vale destacar que a subontologia relativa à Estrutura Organizacional Governamental Brasileira não foi desenvolvida neste trabalho, tendo sido reutilizada [MPOG 2011]. Cada subontologia é apresentada nas subseções seguintes. Além de seus modelos conceituais, exemplos de instanciação obtidos a partir de dados reais sobre o orçamento e as despesas da Universidade Federal do Espírito Santo (UFES), coletados nos sites do SIOP e do Portal da Transparências, são usados para demonstrar a adequação de representação da subontologia proposta. De acordo com [Falbo 2014], a instanciação de uma ontologia é uma maneira de validá-la, pois permite demonstrar que a ontologia é capaz de representar situações de mundo real.

\subsection{Subontologia de Estrutura Organizacional Governamental Brasileira}

Para poder tratar as QCs anteriormente relacionadas, é necessário estabelecer o que é uma unidade organizacional pública e sua estrutura. O site do e-VoG (Repositório de Vocabulários e Ontologias do Governo Eletrônico Brasileiro) apresenta um "Modelo Conceitual para Estruturas Organizacionais Governamentais Brasileiras e o SIORG ${ }^{\circ}$ " publicado em [MPOG 2011], o qual é reutilizado neste trabalho. Os principais tipos ali representados e aqui utilizados fazem parte da subontologia mostrada na Figura 7, sendo definidos da seguinte forma:

\footnotetext{
http://portaltransparencia.gov.br

- SIORG - Sistema de Informações Organizacionais do Governo Federal - contém informações sobre a estrutura organizacional do poder executivo federal (Administração Direta, Autarquias e Fundações), tais como: nomes, códigos e endereços de órgãos públicos e suas unidades administrativas. (https://siorg.planejamento.gov.br/)
} 


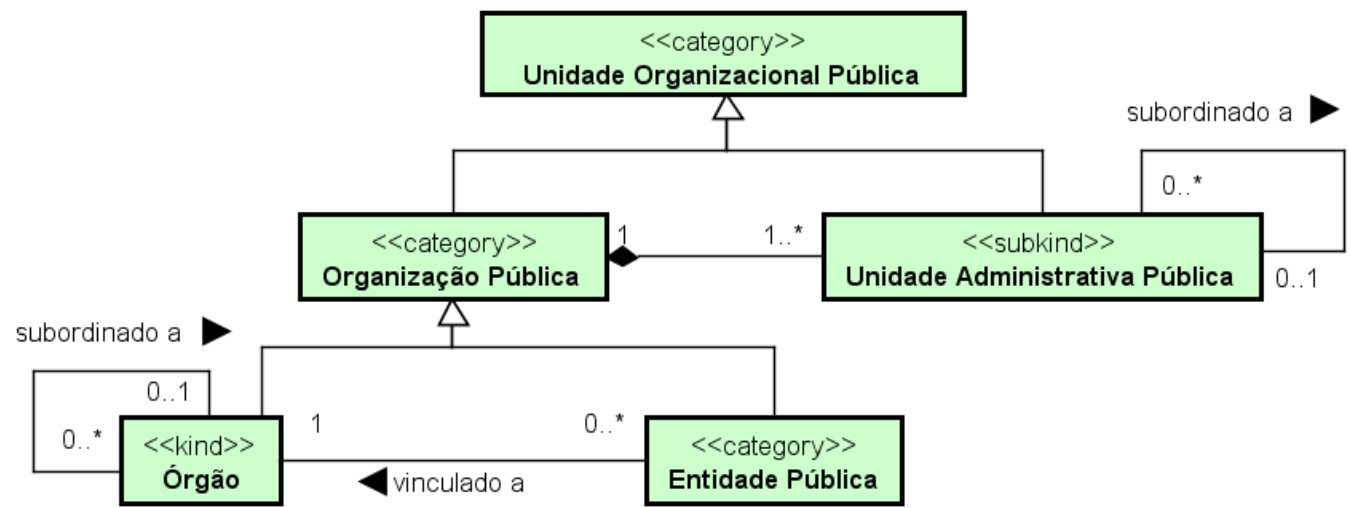

Figura 7. Subontologia de Estrutura Organizacional Governamental (extraída de [Ministério do Planejametno, Desenvolvimento e Gestão 2011]).

(i) Unidade Organizacional Pública é uma generalização que agrega tanto as Organizações Públicas quanto as Unidades Administrativas Públicas que as compõem;

(ii) Organização Pública é uma generalização que agrega os Órgãos e as Entidades Públicas vinculadas a eles. Uma Organização Pública é composta por pelo menos uma Unidade Administrativa Pública;

(iii) Unidade Administrativa Pública integra a administração pública como parte de uma Organização Pública. Suas instâncias podem estar subordinadas a outra unidade do mesmo tipo;

(iv) Órgão é um tipo de Organização Pública, que faz parte da administração direta e cujas instâncias podem estar subordinadas a algum outro órgão;

(v) Entidade Pública é um tipo de Organização Pública com personalidade jurídica própria, autonomia administrativa e financeira, cujas instâncias devem estar vinculadas a um Órgão.

Um exemplo de instanciação dessa subontologia na administração direta federal pode ser o seguinte: o "Campus Santa Teresa" é uma Unidade Administrativa Pública que compõe a Entidade Pública "Instituto Federal do Espírito Santo". Por sua vez, o "Instituto Federal do Espírito Santo" é vinculado ao Órgão "Ministério da Educação", o qual é subordinado ao Órgão "Presidência da República".

\subsection{Subontologia de Autorização Orçamentária}

A Figura 8 apresenta a subontologia que trata da etapa de autorização orçamentária, tendo como conceito central as autorizações de despesa descritas pela LOA. Esta subontologia responde as questões de competência QC1 a QC4. 


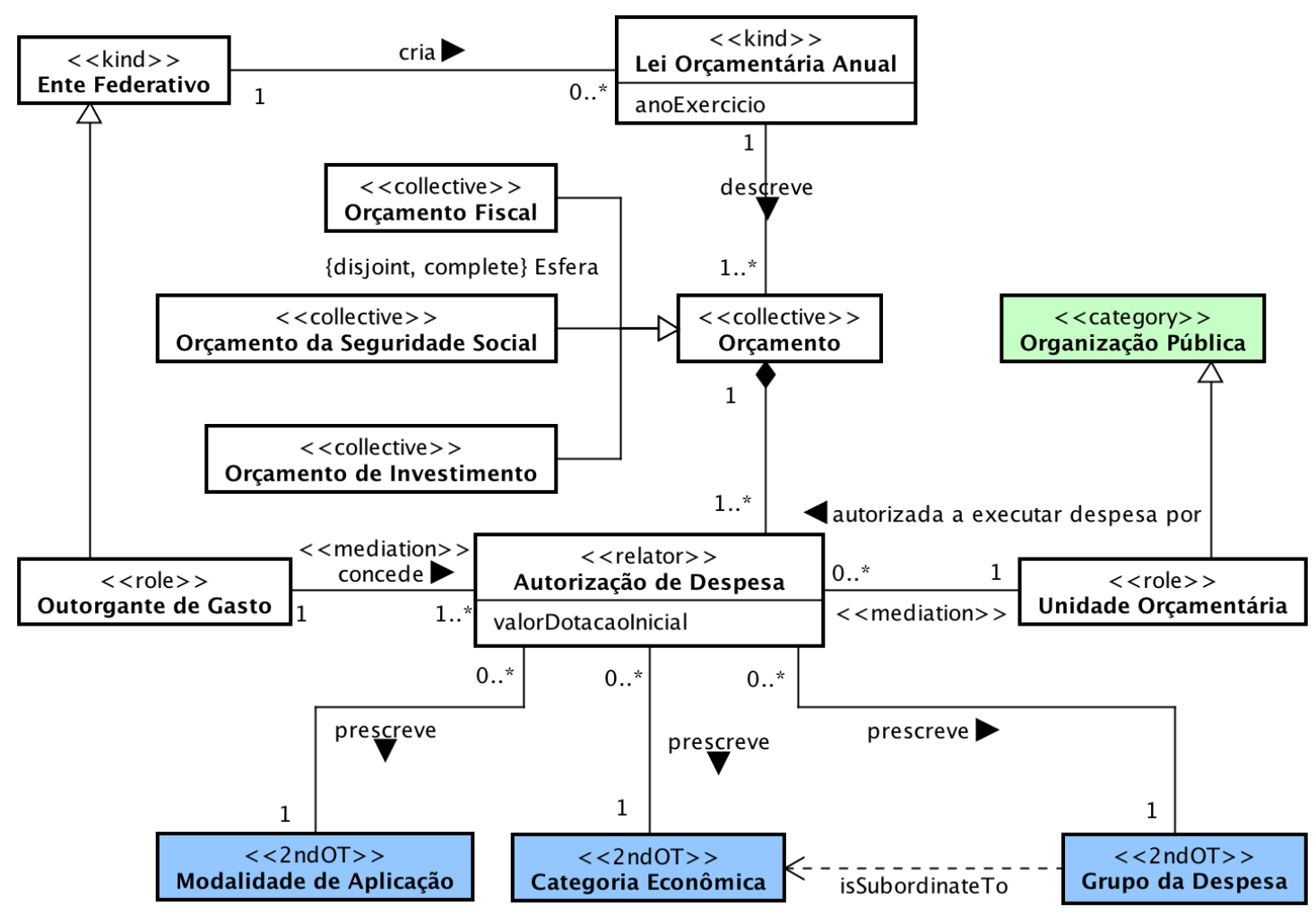

Figura 8. Subontologia de Autorização Orçamentária - Ontologia de Autorização Orçamentária e Execução de Despesa Pública

A Lei Orçamentária Anual descreve um conjunto de Orçamentos (Fiscal, da Seguridade Social ou de Investimento), que representam coleções de Autorizações de Despesa. Autorização de Despesa é representada como uma relação reificada (relator) em que um Ente Federativo (desempenhando o papel de Outorgante de Gasto) concede autorização para uma Unidade Orçamentária (papel desempenhado neste contexto por uma Organização Pública) efetuar despesas até um valor limite (representado pelo atributo "valorDotacaoInicial"). Esta relação de autorização é um relator social do tipo no-right-permission to act [Griffo et al. 2015]), o que significa que há uma permissão para agir sem estar obrigado a tal. O objeto da permissão é a despesa pública, ou seja, a partir da aprovação da LOA, são estabelecidas autorizações para as unidades orçamentárias executarem despesas cujas características estão capturadas no conteúdo de cada Autorização de Despesa.

Para representar a classificação por natureza de despesa, foram incluídas categorias de categorias de despesas modeladas através dos powertypes Modalidade de Aplicação, Categoria Econômica e Grupo da Despesa. Instâncias dessas categorias são também tipos que classificam as despesas, como por exemplo o tipo "Despesas de Capital" (instância de Categoria Econômica) e o tipo "Investimentos" (instância de Grupo da Despesa). A autorização, portanto, é para a realização de despesas de um tipo específico, tipo este capturado no conteúdo da Autorização de Despesa. Por exemplo, uma instância de Autorização de Despesa autorizando gastos com a aquisição de um imóvel faria menção aos tipos "Despesas de Capital" e "Investimentos". Assim a ontologia captura não somente tipos de primeira ordem, mas também tipos de segunda ordem (tipos de tipos), de acordo com a teoria multi-nível MLT [Carvalho and Almeida 2015]. Foi utilizada a relação de subordinação de MLT (isSubordinateTo) para 
representar que instâncias de Grupo de Despesa necessariamente especializam instâncias de Categoria Econômica (p. ex. "Investimentos" é uma especialização de "Despesas de Capital").

Como exemplo de instanciação, seja o caso da autorização de despesa mostrada na Figura 1. Neste caso, o Ente Federativo "União", cria uma Lei Orçamentária Anual para o ano de exercício 2016 ("LOA 2016"). Na "LOA 2016" está descrito um Orçamento Fiscal para o exercício 2016, o qual é composto por diversas Autorizações de Despesas. Dentre as autorizações, consta aquela em que a "União", desempenhando o papel de Outorgante de Gasto, concede autorização ao "Instituto Federal do Espírito Santo", uma Organização Pública que nesse contexto exerce o papel de Unidade Orçamentária. O "Instituto Federal do Espírito Santo", por sua vez, é uma instância de Entidade Pública vinculada ao Órgão "Ministério da Educação". Essa Autorização de Despesa específica prescreve a seguinte classificação para as despesas que poderão ser executadas: (i) Modalidade de Aplicação "90 - Aplicação Direta"; (ii) Categoria Econômica "3 - Despesa Corrente”; (iii) Grupo de Despesa "ODC - Outras Despesas Correntes".

A Tabela 3 mostra os conceitos e relações que respondem as QCs dessa subontologia.

Tabela 3. Tabela de Conceitos/Relações para as QCs da Subontologia de Autorização Orçamentária

\begin{tabular}{|c|c|}
\hline QCs & Conceitos/Relações \\
\hline \multirow[t]{2}{*}{ QC1 } & $\begin{array}{l}\text { Quais despesas uma organização pública está autorizada a realizar de acordo } \\
\text { com a LOA? }\end{array}$ \\
\hline & $\begin{array}{l}\text { Organização Pública especializada em Unidade Orçamentária autorizada a } \\
\text { executar despesa por Autorização de Despesa parte de Orçamento. } \\
\text { Lei Orçamentária Anual descreve Orçamento. }\end{array}$ \\
\hline \multirow[t]{2}{*}{ QC2 } & $\begin{array}{l}\text { Quais classificadores estão prescritos por uma determinada autorização de } \\
\text { despesa? }\end{array}$ \\
\hline & $\begin{array}{l}\text { Autorização de Despesa prescreve: Modalidade de Aplicação, Categoria } \\
\text { Econômica e Grupo da Despesa. }\end{array}$ \\
\hline \multirow[t]{2}{*}{ QC3 } & $\begin{array}{l}\text { Que ente federativo cria uma LOA e, portanto, concede autorizações de } \\
\text { despesa nos orçamentos descritos por essa LOA? }\end{array}$ \\
\hline & $\begin{array}{l}\text { Ente Federativo cria Lei Orçamentária Anual descreve Orçamento. } \\
\text { Autorização de Despesa parte de Orçamento. } \\
\text { Ente Federativo especializado em Outorgante de Gasto concede Autorização } \\
\text { de Despesa. }\end{array}$ \\
\hline \multirow[t]{2}{*}{ QC4 } & Que tipos de orçamentos podem ser descritos em uma LOA? \\
\hline & $\begin{array}{l}\text { Lei Orçamentária Anual descreve Orçamento especializado em: Orçamento } \\
\text { Fiscal, Orçamento da Seguridade Social e Orçamento de Investimento. }\end{array}$ \\
\hline
\end{tabular}




\subsection{Subontologia de Empenho}

Superada a etapa de autorização orçamentária, passa-se para a de execução da despesa pública, na qual o Empenho é o primeiro estágio, sendo definido como um "ato emanado de autoridade competente que cria para o estado a obrigação de pagamento, pendente ou não de implemento de condição" [Tesouro Nacional 2016a]. A Figura 9 apresenta a subontologia que trata do estágio de empenho no processo de execução da despesa pública. Essa subontologia trata as questões de competência QC5 a QC14.

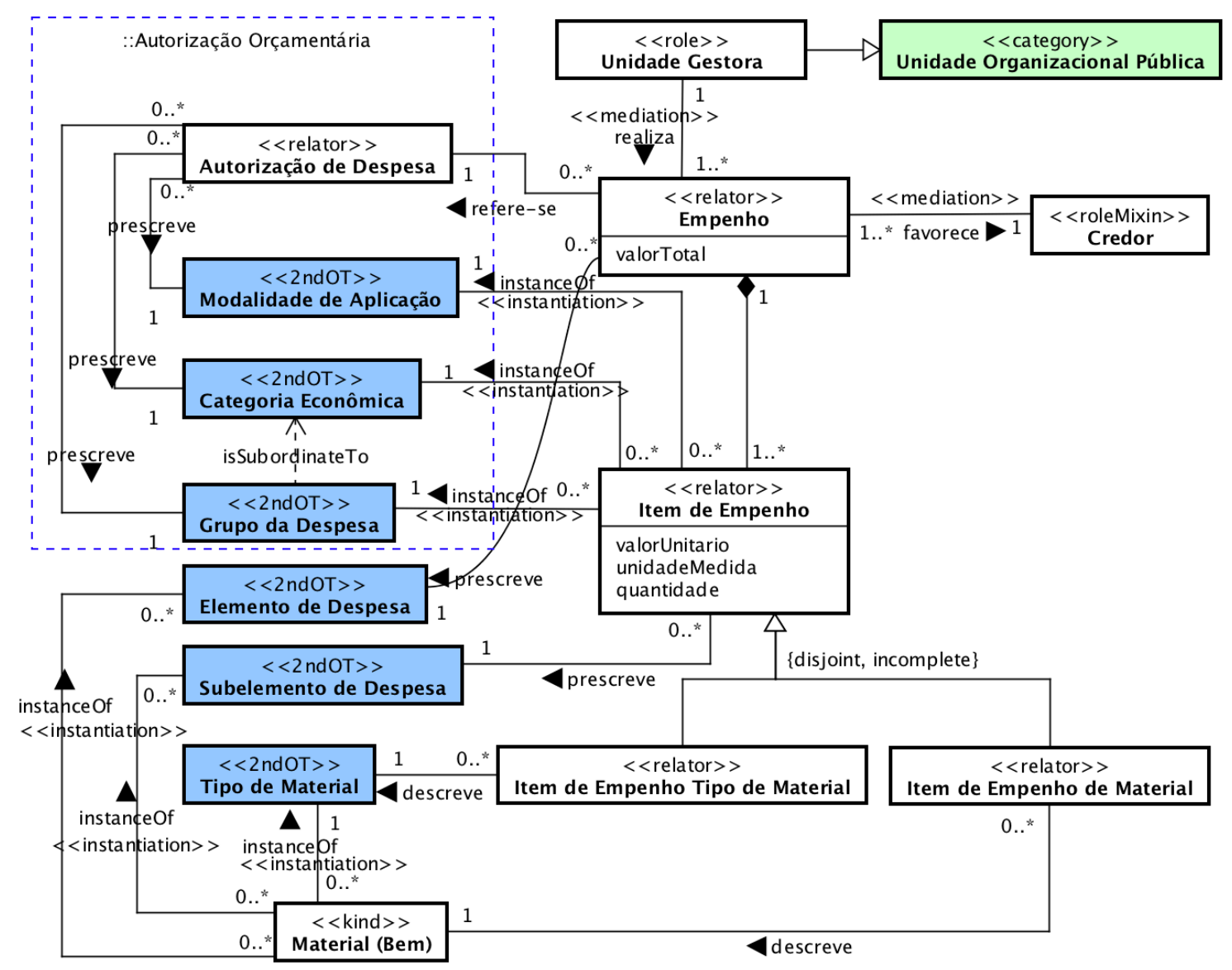

\section{Figura 9. Subontologia de Empenho - Ontologia de Autorização Orçamentária e Execução da Despesa Pública}

O Empenho representa a relação de obrigação da Unidade Gestora (papel desempenhado por uma Unidade Organizacional Pública) para com o Credor, ou favorecido (um roleMixin cujo papel pode ser desempenhado tanto por uma pessoa física, quanto por uma pessoa jurídica). A Unidade Gestora ao realizar um Empenho, garante ao Credor que existe disponibilidade orçamentária para pagar o compromisso assumido. Essa relação é discriminada por meio dos Itens de Empenho (relators) que compõem um Empenho. Portanto, a mesma Unidade Gestora e o mesmo Credor devem estar relacionados (respectivamente por meio das relações mediation "realiza" e "favorece") tanto pelo Empenho, quanto por cada Item de Empenho que o compõe (por uma questão de simplicidade, estas relações mediation foram propositalmente omitidas do diagrama). Adicionalmente, os Itens de Empenho que compõem um Empenho devem instanciar as 
mesmas Modalidade de Aplicação, Categoria Econômica e Grupo da Despesa prescritos pela Autorização de Despesa à qual se refere aquele Empenho.

A classificação da natureza de despesa na etapa de empenho é, portanto, formada tanto por aqueles tipos de segunda ordem prescritos pela Autorização de Despesa na etapa de autorização orçamentária, quanto pelos Elemento de Despesa e Subelemento de Despesa, sendo estes os classificadores mais específicos da despesa pública, especificados somente na etapa de execução da despesa. Sendo assim, cada Empenho prescreve um único Elemento de Despesa, e cada um dos Itens de Empenho que compõe este Empenho pode prescrever um Subelemento de Despesa.

A Figura 10 apresenta um exemplo para explicar essa classificação. O "Empenho Y" é composto do "Item de Empenho Z", que é tipificado por meio dos seguintes classificadores prescritos pela "Autorização de Despesa X": "Despesa Corrente" (instância de Categoria Econômica), "Outra Despesa Corrente" (instância de Grupo da Despesa) e "Aplicação Direta" (instância de Modalidade de Aplicação). Quando o "Empenho Y" refere-se à "Autorização de Despesa X", é necessário que o "Item de Empenho Z" (que compõe o "Empenho Y") seja instância dos mesmos classificadores ("Despesa Corrente", "Outra Despesa Corrente" e "Aplicação Direta") prescritos pela "Autorização de Despesa X".

Para aumentar a precisão da representação e excluir interpretações indesejadas, foram definidos axiomas. Nestes axiomas, foram utilizados os seguintes predicados para representar as relações de instanciação (instance $O f)$ e todo-parte (partOf):

- instanceOf(e, t): relação instância de (instance of), onde a entidade e é instância de uma entidade do tipo t. MLT admite que tipos tenham indivíduos como instâncias, bem como outros tipos. Para lidar com a variedade de tipos em uma configuração multi-nível, a noção de ordem de tipos (type order) é usada. Tipos cujas instâncias são indivíduos são ditos tipos de primeira-ordem. Tipos cujas instâncias são tipos de primeira-ordem são ditos tipos de segunda-ordem, e assim sucessivamente [Carvalho and Almeida 2016].

- $\operatorname{partOf(p,~w):~relação~antissimétrica,~não-transitiva~e~irreflexiva~entre~duas~}$ instâncias, onde uma instância pé parte de outra instância w. 


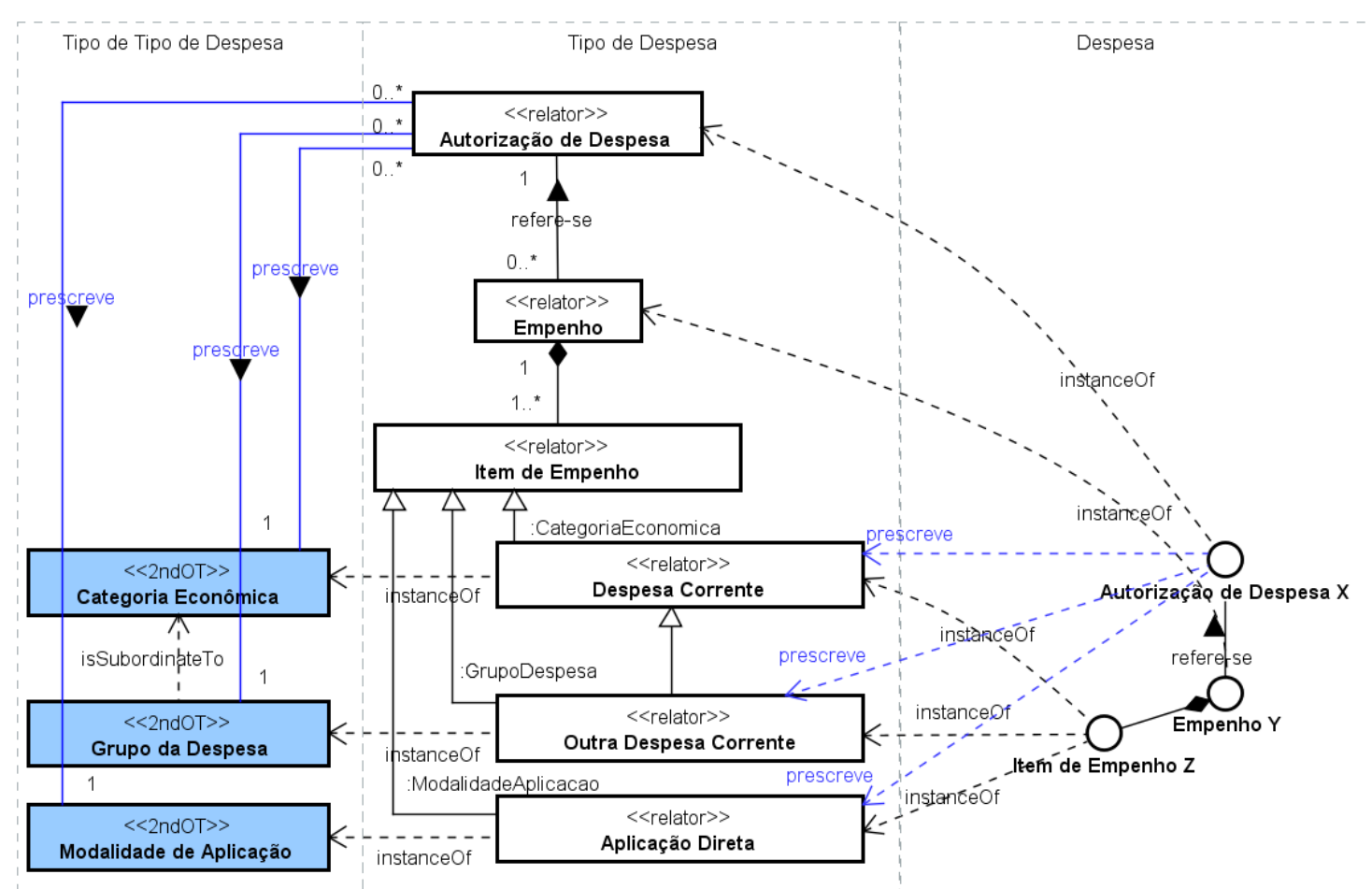

Figura 10. Exemplo de classificação da despesa usando tipos de segunda ordem.

Para garantir que todo Item de Empenho respeite a classificação prescrita na Autorização de Despesa, tem-se o axioma A1.

A1 Se um Empenho $\boldsymbol{e}$ se refere a uma Autorização da Despesa ad, então todo Item de Empenho ie que for parte de $\boldsymbol{e}$, deve instanciar os tipos prescritos na Autorização da Despesa $\boldsymbol{a d}$, a saber: a Modalidade da Aplicação ma , a Categoria Econômica $\boldsymbol{c e}$ e o Grupo de Despesa $\boldsymbol{g d}$.

$\forall$ e: Empenho, ad: AutorizacaoDespesa,ma: ModalidadeAplicacao, ce: CategoriaEconomica, gd: GrupoDespesa refereSe $(e, a d)$

$\wedge$ prescreve $(a d, m a) \wedge$ prescreve $(a d, c e) \wedge \operatorname{prescreve}(a d, g d)$

$\rightarrow(\forall$ ie: ItemEmpenho partOf $(i e, e)$

$\rightarrow$ instanceOf $(i e, m a) \wedge$ instanceOf $(i e, c e) \wedge$ instanceOf $(i e, g d))$

É importante notar que, na Figura 10, as instâncias dos tipos de segunda ordem Categoria Econômica, Grupo de Despesa e Modalidade de Aplicação (chamados de classificadores das despesas públicas) são, de fato, especializações de Item de Empenho. Ou seja, cada um desses tipos de segunda ordem impõe um critério de classificação (definindo um generalization set correspondente) para Item de Empenho. Por exemplo, o generalization set formado pelos tipos "Despesa Corrente" e "Despesa de Capital" (este último omitido na Figura 10) define uma especialização do tipo Item de Empenho a partir do critério de classificação imposto pelo tipo de segunda ordem Categoria Econômica.

Retomando a explicação da subontologia mostrada na Figura 9, Item de Empenho de Material e Item de Empenho de Tipo de Material são especializações de Item de Empenho que descrevem, respectivamente, um Material (Bem) e um Tipo de 
Material (tipo de segunda ordem, conforme MLT). Para exemplificar, pode-se considerar o indivíduo "Veículo Chassi 9BW ZZZ377 VT 004251" como uma instância de Material (Bem), enquanto pode-se considerar como instância de Tipo de Material o tipo "Veículo Marca Honda, Modelo City, Ano 2016. A instância de Material (Bem) "Veículo Chassi 9BW ZZZ377 VT 004251" pode ser simultaneamente uma instância de: (i) "Equipamentos e Material Permanente" - que por sua vez é uma instância do classificador Elemento de Despesa (tipo de segunda ordem de acordo com MLT)); e (ii) "Veículos e Equipamentos de Transporte e Serviços" - que é uma instância do classificador Subelemento de Despesa (também um tipo de segunda ordem).

O axioma A2 é definido para garantir que o Subelemento de Despesa prescrito por um Item de Empenho deve ser instanciado pelo Material (Bem) que é descrito por este mesmo item. O axioma A3, por sua vez, visa garantir que o Material (Bem) descrito em um Item de Empenho de Material é instância do Elemento de Despesa prescrito pelo Empenho do qual o item é parte.

\begin{tabular}{|c|c|}
\hline \multirow[t]{2}{*}{ A2 } & $\begin{array}{l}\text { Se um Item de Empenho de Material iem prescreve o Subelemento de Despesa } \boldsymbol{s} \boldsymbol{d} \\
\text { e descreve o Material (Bem) } \boldsymbol{m} \text {, então } \boldsymbol{m} \text { deve ser instância de } \boldsymbol{s} \boldsymbol{d} \text {. }\end{array}$ \\
\hline & $\begin{array}{l}\forall \text { iem: ItemEmpenhoMaterial, sd: SubelementoDespesa, } m: \text { MaterialBem } \\
\text { prescreve }(\text { iem, } s d) \wedge \text { descreve }(\text { iem, } m) \rightarrow \text { instanceOf }(m, s d)\end{array}$ \\
\hline \multirow[t]{2}{*}{ A3 } & $\begin{array}{l}\text { Se um Item de Empenho de Material iem descreve o Material (Bem) } \boldsymbol{m} \text { e é parte } \\
\text { de um Empenho } \boldsymbol{e} \text { que prescreve o Elemento de Despesa } \boldsymbol{e d} \text {, então } \boldsymbol{m} \text { deve ser } \\
\text { instância de } \boldsymbol{e d} \text {. }\end{array}$ \\
\hline & $\begin{array}{l}\forall \text { iem: ItemEmpenhoMaterial, } \text { : Empenho, ed: ElementoDespesa, } \\
\text { m: MaterialBem partOf }(\text { iem, } e) \wedge \operatorname{prescreve}(e, e d) \\
\wedge \text { descreve }(i e m, m) \rightarrow \text { instance } O f(m, e d)\end{array}$ \\
\hline
\end{tabular}

Vale lembrar que o escopo da ontologia de referência aqui apresentada trata apenas da execução de despesas públicas com aquisição de material de consumo ou material permanente (bem), representados pelos conceitos Material (Bem) e Tipo de Material. Por esse motivo, o generalization set de Item de Empenho na Figura 9 é caracterizado como incomplete, ou seja, apresenta apenas como especialização Item de Empenho de Material e Item de Empenho de Tipo de Material. De forma análoga, nas subontologias de liquidação e pagamento apresentadas nas seções seguintes, há generalization sets de Item de Liquidação (especializado em Item de Liquidação de Material) e de Item de Pagamento (especializado em Item de Pagamento de Material) também incompletos, modelando somente liquidações e pagamentos desses tipos de itens. Porém, essa decisão de modelagem possibilita que sejam adicionadas novas especializações no futuro, contemplando, p. ex., a execução de despesas com serviços, pensões, indenizações, subvenções, correções, juros etc.

A Tabela 4 mostra os conceitos, relações, propriedades e axiomas que respondem as QCs dessa subontologia. 
Tabela 4. Tabela de Conceitos, Relações e Propriedades para as QCs da Subontologia de Empenho

\begin{tabular}{|c|c|}
\hline QCs & Conceitos/Relações/Propriedades \\
\hline \multirow[t]{2}{*}{ QC5 } & $\begin{array}{l}\text { Quais empenhos foram feitos tendo como base uma determinada autorização } \\
\text { de despesa? }\end{array}$ \\
\hline & Empenho refere-se Autorização de Despesa. \\
\hline \multirow[t]{2}{*}{ Q6 } & Qual é a unidade gestora e o credor de um empenho? \\
\hline & Unidade Gestora realiza Empenho favorece Credor. \\
\hline \multirow[t]{2}{*}{ QC7 } & $\begin{array}{l}\text { Quais itens, relativos a materiais de consumo ou bens, foram empenhados em } \\
\text { determinado empenho e quais foram as quantidades e valores associados a } \\
\text { cada um dos itens? }\end{array}$ \\
\hline & $\begin{array}{l}\text { Empenho tem como parte Item de Empenho especializado em: Item de } \\
\text { Empenho de Material e Item de Empenho de Tipo de Material. } \\
\text { Item de Empenho especifica: quantidade e valorUnitario. }\end{array}$ \\
\hline \multirow[t]{2}{*}{ QC8 } & $\begin{array}{l}\text { Como é classificado um material descrito em um determinado item de } \\
\text { empenho? }\end{array}$ \\
\hline & $\begin{array}{l}\text { Item de Empenho especializado em Item de Empenho de Material descreve } \\
\text { Material (Bem). } \\
\text { Item de Empenho parte de Empenho prescreve Elemento de Despesa. } \\
\text { Item de Empenho prescreve Subelemento de Despesa. }\end{array}$ \\
\hline \multirow[t]{2}{*}{ QC9 } & $\begin{array}{l}\text { Quais são os classificadores dos itens que compõem um determinado } \\
\text { empenho? }\end{array}$ \\
\hline & $\begin{array}{l}\text { Empenho tem como parte Item de Empenho instanceOf: Modalidade de } \\
\text { Aplicação, Categoria Econômica e Grupo da Despesa. } \\
\text { Empenho prescreve Elemento de Despesa. } \\
\text { Item de Empenho prescreve Subelemento de Despesa. }\end{array}$ \\
\hline \multirow[t]{2}{*}{ QC10 } & $\begin{array}{l}\text { Quais unidades gestoras empenharam recursos de uma determinada } \\
\text { autorização de despesa? }\end{array}$ \\
\hline & Unidade Gestora realiza Empenho refere-se Autorização de Despesa. \\
\hline \multirow[t]{2}{*}{ QC11 } & $\begin{array}{l}\text { Quais credores foram favorecidos com empenhos relacionados a uma } \\
\text { determinada autorização de despesa? }\end{array}$ \\
\hline & $\begin{array}{l}\text { Empenho favorece Credor. } \\
\text { Empenho refere-se Autorização de Despesa. }\end{array}$ \\
\hline \multirow[t]{2}{*}{ QC12 } & Em um exercício fiscal, quanto foi empenhado a determinado credor? \\
\hline & $\begin{array}{l}\text { Lei Orçamentária Anual descreve Orçamento tem como parte Autorização de } \\
\text { Despesa. } \\
\text { Empenho refere-se a Autorização de Despesa. } \\
\text { Empenho favorece Credor. } \\
\text { Empenho especifica valorTotal. }\end{array}$ \\
\hline
\end{tabular}


Tabela 4. Tabela de Conceitos, Relações e Propriedades para as QCs da Subontologia de Empenho (continuação)

\begin{tabular}{|c|l|}
\hline QCs & \multicolumn{1}{|c|}{ Conceitos/Relações/Propriedades } \\
\hline QC13 & $\begin{array}{l}\text { Em um exercício fiscal, qual valor empenhado para determinado classificador } \\
\text { de despesa? }\end{array}$ \\
\cline { 2 - 3 } & $\begin{array}{l}\text { Lei Orçamentária Anual descreve Orçamento tem como parte Autorização de } \\
\text { Despesa. } \\
\text { Empenho refere-se Autorização de Despesa. } \\
\text { Autorização de Despesa prescreve: Modalidade de Aplicação, Categoria } \\
\text { Econômica e Grupo da Despesa. } \\
\text { Empenho prescreve Elemento de Despesa. } \\
\text { Empenho tem como parte Item de Empenho prescreve Subelemento de } \\
\text { Despesa. } \\
\text { Item de Empenho especifica valorUnitario. }\end{array}$ \\
\hline \multirow{2}{*}{ QC14 } & $\begin{array}{l}\text { Em um exercício fiscal, qual o valor empenhado por uma determinada } \\
\text { unidade gestora? }\end{array}$ \\
\cline { 2 - 2 } \\
$\begin{array}{l}\text { Lei Orçamentária Anual descreve Orçamento. } \\
\text { Unidade Gestora realiza Empenho refere-se Autorização de Despesa parte de } \\
\text { Orçamento. } \\
\text { Empenho especifica valorTotal. }\end{array}$ \\
\hline
\end{tabular}

\subsection{Subontologia de Liquidação}

Seguindo o processo de execução da despesa pública, após o estágio de empenho, é realizada a liquidação. Os conceitos relativos a esse estágio do processo de execução da despesa pública são apresentados na subontologia mostrada na Figura 11. Essa subontologia trata as questões de competência QC15 a QC22.

A Liquidação ocorre somente se existir Empenho prévio (relação “depende") no processo de execução da despesa pública. A Liquidação é um relator que reifica a relação na qual uma Unidade Gestora concede a quitação a um Credor pela entrega (que pode ser parcial) de algum material que tenha sido empenhado. Uma Liquidação é composta por Itens de Liquidação, os quais são igualmente relators conectando a mesma Unidade Gestora e o mesmo Credor daquela Liquidação da qual eles fazem parte.

Um Item de Liquidação de Material é um subtipo de Item de Liquidação que adicionalmente conecta os Materiais Liquidados (relação mediation liquida) à Unidade Gestora e ao Credor. Em outras palavras, um Item de Liquidação de Material é um relator ternário conectando Materiais Liquidados a uma Unidade Gestora e um Credor. 


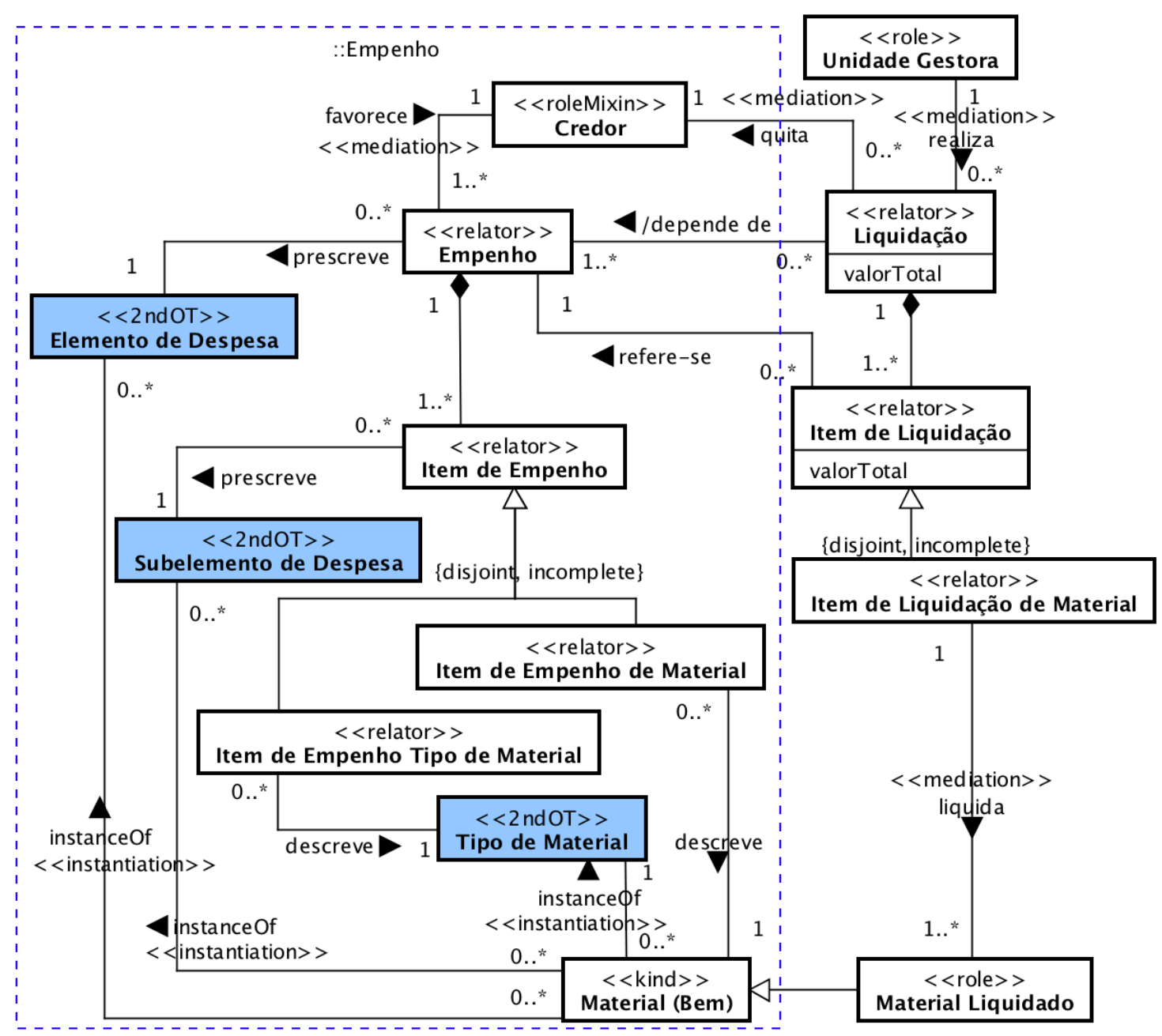

Figura 11. Subontologia de Liquidação - Ontologia de Autorização Orçamentária e Execução da Despesa Pública

Para garantir que cada Item de Liquidação refere-se a um Empenho e faz parte de uma Liquidação que depende desse mesmo Empenho, foi definido o axioma A4. O axioma A5, por sua vez, visa garantir que a Unidade Gestora e o Credor são os mesmos nos estágios de empenho e de liquidação para uma determinada despesa pública.

A4 Se um Empenho $\boldsymbol{e}$ depende de uma Liquidação $\boldsymbol{l}$, então existe um Item de Liquidação $\boldsymbol{i} \boldsymbol{l}$ que faz parte da Liquidação $\boldsymbol{l}$ e o Item de Liquidação $\boldsymbol{i l}$ se refere ao Empenho $\boldsymbol{e}$.

$\forall$ e: Empenho, l: Liquidacao, il: ItemLiquidacao refereSe(il,e) $\wedge \operatorname{partOf}(i l, l) \rightarrow$ depende $(l, e)$

A5 Para todo Empenho $\boldsymbol{e}$ e Liquidação $\boldsymbol{l}$ que depende de $\boldsymbol{e}$, deve existir uma única Unidade Gestora $\boldsymbol{u g}$ e um único Credor $\boldsymbol{c}$, tal que $\boldsymbol{u g}$ realiza o Empenho $\boldsymbol{e}, \boldsymbol{e}$ favorece $\boldsymbol{c}, \boldsymbol{u} \boldsymbol{g}$ realiza a Liquidação $\boldsymbol{l}$, e $\boldsymbol{l}$ quita $\boldsymbol{c}$.

$\forall$ e: Empenho, l: Liquidacao depende $(l, e)$

$\rightarrow \exists$ ug: UnidadeGestora, $c$ : Credor realiza $(u g, e)$

$\wedge$ favorece $(e, c) \wedge$ realiza $(u g, l) \wedge$ quita $(l, c)$ 
Dependendo dos tipos de Item de Empenho (Item de Empenho de Tipo de Material ou Item de Empenho de Material), há duas situações a serem consideradas no momento da liquidação desses itens:

1. Um determinado Empenho é composto por uma instância de Item de Empenho de Tipo de Material, a qual descreve, p.ex., o tipo "Veículo Marca VW, Modelo Up, Ano 2016" como instância de Tipo de Material.

Neste caso, uma instância de Liquidação, que depende daquele Empenho é composta por um Item de Liquidação de Material (que se refere àquele mesmo Empenho) o qual liquida a instância de Material Liquidado "Veículo Chassi 9BW ZZZ377 VT 004251”, que, por sua vez, deve ser instância do Tipo de Material "Veículo Marca VW, Modelo Up, Ano 2016" descrito pelo Item de Empenho de Tipo de Material.

2. Um dado Empenho é composto por uma instância de Item de Empenho de Material a qual descreve a aquisição de uma instância de Material (Bem) específico, tal como uma "Área Urbana localizada no endereço ABC e com dimensões XYZ" (trata-se aqui da descrição de um indivíduo e não de um tipo, diferente do caso anterior).

Neste caso, a instância de Liquidação, que depende daquele Empenho, é composta por um Item de Liquidação de Material (que se refere àquele mesmo Empenho) o qual liquida a instância de Material Liquidado "Área Urbana localizada no endereço ABC e com dimensões XYZ”, que está descrita pela instância de Item de Empenho de Material.

O axioma A6 visa garantir que um Material Liquidado é instância do Tipo de Material descrito pelo Item de Empenho de Tipo de Material (caso 1); ou alternativamente, que o Material Liquidado é o mesmo tanto para o Item de Liquidação que o liquida quanto para o Item de Empenho de Material que o descreve (caso 2).

\begin{tabular}{|c|c|}
\hline \multirow[t]{2}{*}{ A6 } & $\begin{array}{l}\text { Para todo Material Liquidado } \boldsymbol{m l} \text { liquidado por um Item de Liquidação de } \\
\text { Material } \boldsymbol{i l} \boldsymbol{m} \text { que se refere ao Empenho } \boldsymbol{e} \text {, deve existir um Item de Empenho } \boldsymbol{i} \boldsymbol{e} \\
\text { que é parte de } \boldsymbol{e} \text { e, ou: (1) } \boldsymbol{i} \boldsymbol{e} \text { é um Item de Empenho de Material que descreve } \boldsymbol{m} \boldsymbol{l} \text {, } \\
\text { ou, (2) } \boldsymbol{i} \boldsymbol{e} \text { é um Item de Empenho Tipo Material que descreve o Tipo de Material } \\
\boldsymbol{t} \boldsymbol{m} \text { do qual } \boldsymbol{m} \boldsymbol{l} \text { é uma instância. }\end{array}$ \\
\hline & $\begin{array}{l}\forall \text { ml: MaterialLiquidado, ilm: ItemLiquidacaoMaterial, } e: \text { Empenho } \\
\text { liquida }(\text { ilm, } m l) \wedge \text { refereSe }(\text { ilm, } e) \\
\rightarrow \exists \text { ie:ItemEmpenho partof }(\text { ie }, e) \wedge \\
((\text { ItemEmpenhoMaterial }(\text { ie }) \wedge \text { descreve }(\text { ie }, m l)) \vee \\
(\exists \text { tm:TipoMaterial ItemEmpenhoTipoMaterial }(i e) \wedge \operatorname{descreve}(\mathrm{ie}, \mathrm{tm}) \\
\wedge \text { instanceO }(\mathrm{ml}, \mathrm{tm})))\end{array}$ \\
\hline
\end{tabular}

A Tabela 5 mostra os conceitos, relações, propriedades e axiomas que respondem as QCs dessa subontologia. 
Tabela 5. Tabela de Conceitos, Relações e Propriedades para as QCs da Subontologia de Liquidação

\begin{tabular}{|c|c|}
\hline QCs & Conceitos/Relações/Propriedades \\
\hline \multirow[t]{2}{*}{ QC15 } & Qual é a unidade gestora e o credor de uma liquidação? \\
\hline & Unidade Gestora realiza Liquidação quita Credor. \\
\hline \multirow[t]{3}{*}{ QC16 } & $\begin{array}{l}\text { Quais os itens, relativos a materiais de consumo ou bens, foram liquidados } \\
\text { em determinada liquidação e quais foram os valores associados a cada um } \\
\text { dos itens? }\end{array}$ \\
\hline & $\begin{array}{l}\text { Item de Liquidação de Material especialização de Item de Liquidação parte } \\
\text { de Liquidação. }\end{array}$ \\
\hline & Item de Liquidação especifica valorTotal. \\
\hline \multirow[t]{2}{*}{ QC17 } & A quais empenhos se referem uma liquidação e seus itens? \\
\hline & Liquidação tem como parte Item de Liquidação refere-se Empenho. \\
\hline \multirow[t]{2}{*}{ QC18 } & Quais os materiais liquidados por um item de liquidação? \\
\hline & $\begin{array}{l}\text { Item de Liquidação especializado em Item de Liquidação de Material } \\
\text { liquida Material Liquidado especialização de Material (Bem) }\end{array}$ \\
\hline \multirow[t]{2}{*}{ QC19 } & $\begin{array}{l}\text { Quais liquidações foram feitas tendo como base uma determinada } \\
\text { autorização de despesa? }\end{array}$ \\
\hline & Liquidação depende de Empenho refere-se Autorização de Despesa. \\
\hline \multirow[t]{2}{*}{ QC20 } & Em um exercício fiscal, quanto foi liquidado a um determinado credor? \\
\hline & $\begin{array}{l}\text { Lei Orçamentária Anual descreve Orçamento. } \\
\text { Liquidação depende de Empenho refere-se Autorização de Despesa parte } \\
\text { de Orçamento. } \\
\text { Liquidação quita Credor. } \\
\text { Liquidação especifica valorTotal. }\end{array}$ \\
\hline \multirow[t]{2}{*}{ QC21 } & $\begin{array}{l}\text { Em um exercício fiscal, qual valor liquidado para determinado classificador } \\
\text { de despesa? }\end{array}$ \\
\hline & $\begin{array}{l}\text { Lei Orçamentária Anual descreve Orçamento tem como parte Autorização } \\
\text { de Despesa prescreve Modalidade de Aplicação, Categoria Econômica e } \\
\text { Grupo de Despesa. } \\
\text { Empenho refere-se Autorização de Despesa. } \\
\text { Liquidação depende de Empenho. } \\
\text { Empenho prescreve Elemento de Despesa. } \\
\text { Empenho tem como parte Item de Empenho prescreve Subelemento de } \\
\text { Despesa. } \\
\text { Liquidação especifica valorTotal. }\end{array}$ \\
\hline \multirow[t]{2}{*}{ QC22 } & $\begin{array}{l}\text { Em um exercício fiscal, quanto foi liquidado por uma determinada unidade } \\
\text { gestora? }\end{array}$ \\
\hline & $\begin{array}{l}\text { Lei Orçamentária Anual descreve Orçamento tem como parte Autorização } \\
\text { de Despesa. } \\
\text { Liquidação depende de Empenho refere-se Autorização de Despesa. } \\
\text { Unidade Gestora realiza Liquidação especifica valorTotal. }\end{array}$ \\
\hline
\end{tabular}




\subsection{Subontologia de Pagamento}

O último estágio no processo de execução da despesa pública é o pagamento, que está representado na subontologia mostrada na Figura 12. Essa subontologia trata das questões de competência QC23 a QC30.

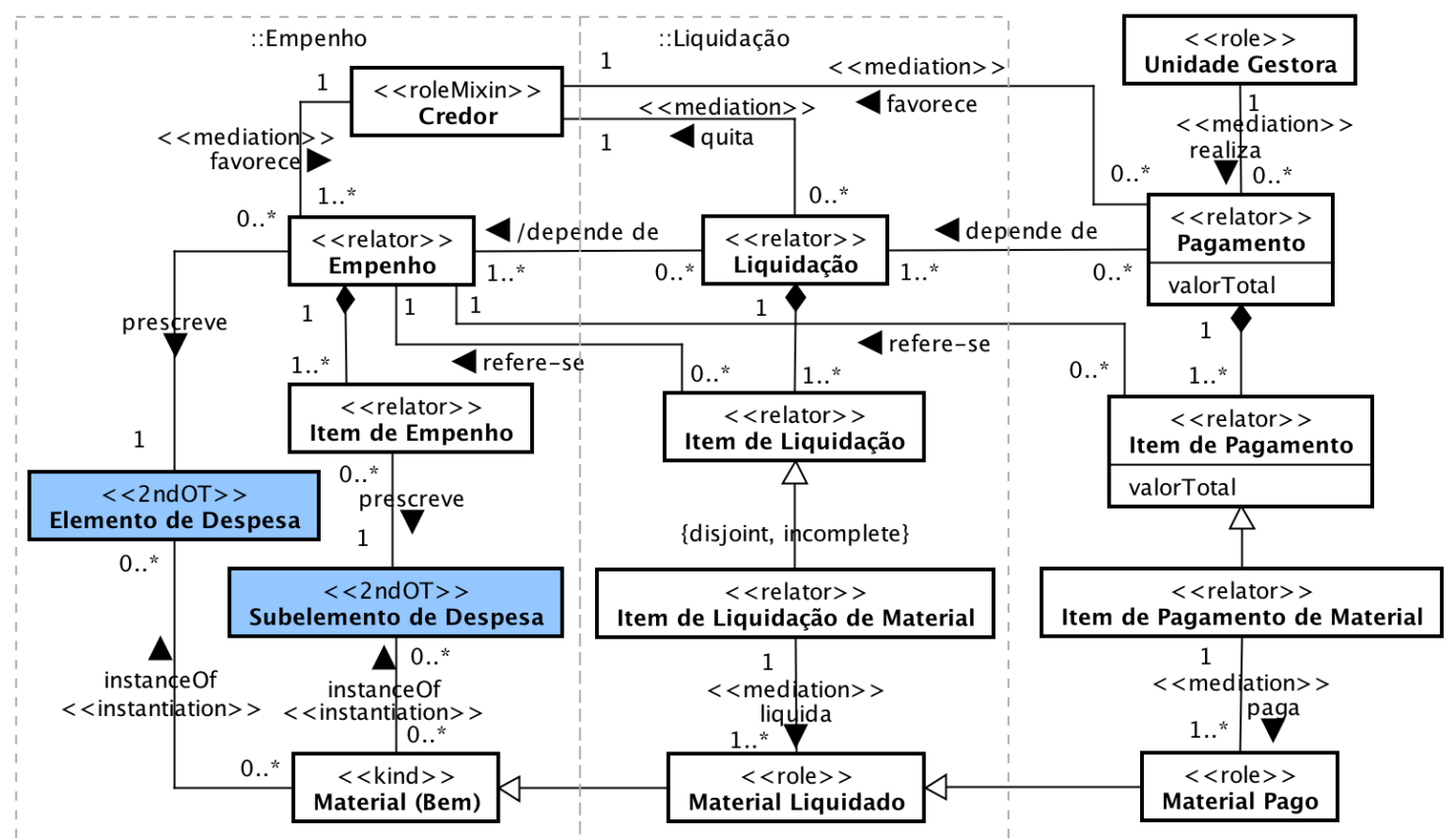

Figura 12. Subontologia de Pagamento - Ontologia de Autorização Orçamentária e Execução da Despesa Pública

Pagamento é um relator que reifica a relação na qual uma Unidade Gestora da administração pública realiza o repasse de numerário em favor de um Credor. $\mathrm{O}$ Pagamento é efetuado mediante prévia Liquidação, o que está representado na subontologia pela relação "depende de" entre essas entidades. Um Pagamento é composto por Itens de Pagamento, os quais também são relators que conectam a mesma Unidade Gestora e Credor daquele Pagamento o qual eles fazem parte.

O Item de Pagamento de Material é um relator ternário (tal como o Item de Liquidação de Material) que especializa Item de Pagamento, e relaciona Materiais Pagos a uma Unidade Gestora e um Credor (esses últimos são os mesmos daquele Pagamento ao qual ele faz parte). Já o Material Pago é uma especialização de Material Liquidado e, por conseguinte, um papel representado por Material (Bem). Vale observar que, como os Itens de Pagamento que compõem um Pagamento podem se referir a Empenhos diferentes, é possível que um Pagamento dependa de várias Liquidações e Empenhos.

O axioma A7 foi definido a fim de garantir que cada Item de Pagamento faz parte de um Pagamento e refere-se a um Empenho, sendo que aquele Pagamento depende de uma Liquidação a qual, por sua vez, depende daquele mesmo Empenho. O axioma A8, por sua vez, garante que a Unidade Gestora e o Credor são os mesmos nos estágios de liquidação e pagamento de uma despesa (de forma similar, o axioma A5 trata deste mesmo aspecto para os estágios de empenho e liquidação). 
A7 Para toda Liquidação $\boldsymbol{l}$ da qual um Pagamento $\boldsymbol{p}$ depende, existe um Empenho $\boldsymbol{e}$ e um Item de Pagamento ip tal que $\boldsymbol{i p}$ é parte de $\boldsymbol{p}, \boldsymbol{l}$ depende de $\boldsymbol{e}$ e $\boldsymbol{i} \boldsymbol{p}$ se refere a este mesmo $\boldsymbol{e}$.

$\forall$ l: Liquidacao, $p:$ Pagamento depende $(p, l)$

$\rightarrow \exists$ e: Empenho,ip:ItemPagamento refere_se(ip,e)

$\wedge \operatorname{partOf}(i p, p) \wedge$ depende $(l, e)$

A8 Para toda Liquidação $\boldsymbol{l}$ e Pagamento $\boldsymbol{p}$ em que $\boldsymbol{p}$ depende de $\boldsymbol{l}$, deve existir uma única Unidade Gestora $\boldsymbol{u g}$ e um único Credor $\boldsymbol{c}$, tal que $\boldsymbol{u g}$ realiza a Liquidação $\boldsymbol{l}$, $\boldsymbol{l}$ quita $\boldsymbol{c}, \boldsymbol{u g}$ realiza o Pagamento $\boldsymbol{p}$ e $\boldsymbol{p}$ favorece $\boldsymbol{c}$.

$\forall$ l: Liquidacao, $p:$ Pagamento depende $(p, l) \rightarrow$

$\exists$ ug: UnidadeGestora, $c$ : Credor realiza $(u g, l) \wedge$ quita $(l, c) \wedge$ realiza $(u g, p) \wedge \operatorname{paga}(p, c)$

A Tabela 6 apresenta os conceitos e relações para as QCs relativas a essa subontologia.

Tabela 6. Tabela de Conceitos, Relações e Propriedades para as QCs relativas a Subontologia de Pagamento

\begin{tabular}{|c|l|}
\hline QCs & \multicolumn{1}{c|}{ Conceitos/Relações } \\
\hline \multirow{2}{*}{ QC23 } & $\begin{array}{l}\text { Qual é a unidade gestora que realizou um pagamento e qual o credor } \\
\text { favorecido por esse pagamento? }\end{array}$ \\
\cline { 2 - 3 } QC24 & Unidade Gestora realiza Pagamento favorece Credor. \\
\cline { 2 - 3 } Qe quais liquidações um pagamento depende?
\end{tabular}


Tabela 6. Tabela de Conceitos, Relações e Propriedades para as QCs relativas a Subontologia de Pagamento (continuação)

\begin{tabular}{|c|c|}
\hline QCs & Conceitos/Relações \\
\hline \multirow[t]{2}{*}{ QC29 } & Em um exercício fiscal, quanto foi pago por determinada unidade gestora? \\
\hline & $\begin{array}{l}\text { Lei Orçamentária Anual descreve Orçamento tem como parte Autorização } \\
\text { de Despesa } \\
\text { Unidade Gestora realiza Pagamento tem como parte Item Pagamento } \\
\text { refere-se Empenho refere-se Autorização de Despesa. } \\
\text { Pagamento especifica valorTotal. }\end{array}$ \\
\hline \multirow[t]{2}{*}{ QC30 } & $\begin{array}{l}\text { Em um exercício fiscal, qual foi o valor total pago para determinado } \\
\text { classificador da despesa? }\end{array}$ \\
\hline & $\begin{array}{l}\text { Considerando os classificadores Modalidade de Aplicação, Categoria } \\
\text { Econômica e Grupo de Despesa: } \\
\text { Lei Orçamentária Anual descreve Orçamento tem como parte } \\
\text { Autorização de Despesa prescreve: Modalidade de Aplicação, Categoria } \\
\text { Econômica e Grupo da Despesa. } \\
\text { Item de Pagamento refere-se Empenho refere-se Autorização de Despesa. } \\
\text { Item de Pagamento especifica valorTotal. } \\
\text { Considerando os classificadores Elemento de Despesa e Subelemento de } \\
\text { Despesa: } \\
\text { Lei Orçamentária Anual descreve Orçamento tem como parte } \\
\text { Autorização de Despesa. } \\
\text { Item de Pagamento refere-se Empenho refere-se Autorização de Despesa. } \\
\text { Item de Pagamento especializado em Item de Pagamento de Material } \\
\text { paga Material Pago especialização de Material Liquidado especialização } \\
\text { de Material(Bem) instanceOf: Elemento de Despesa e Subelemento de } \\
\text { Despesa. } \\
\text { Item de Pagamento especifica valorTotal. }\end{array}$ \\
\hline
\end{tabular}

\section{Usando ORDP para Integrar Dados Orçamentários}

A fim de avaliar o potencial de ORDP para apoiar iniciativas de integração de dados orçamentários, foi realizada uma prova de conceito utilizando tecnologias da Web Semântica para desenvolver aplicações que integram dados sobre execução da despesa pública extraídos do Portal da Transparência do governo federal e dados sobre autorização orçamentária obtidos por meio do endpoint do SIOP.

Segundo [Nunamaker 1991 apud Hevner e Chatterjee 2010], o desenvolvimento de aplicações como protótipos pode ser usado como prova de conceito para demonstrar aplicabilidade tanto do processo de desenvolvimento quanto do próprio artefato projetado. Neste caso, procura-se demonstrar que o artefato criado no esforço de pesquisa é capaz de tratar diretamente o problema previamente identificado [Hevner e Chatterjee 2010].

Portanto, neste trabalho demonstra-se a aplicabilidade de ORDP por meio do desenvolvimento de aplicações, que servem como prova de conceito em uma situação 
real, utilizando dados referentes à Universidade Federal do Espírito Santo (UFES), vinculada ao Ministério da Educação. Assim, é possível evidenciar a cobertura dos conceitos do domínio pela ORDP e sua capacidade de apoiar a integração de dados publicados pelo governo federal referentes à etapa de autorização orçamentária (endpoint do SIOP), com aqueles da etapa de execução da despesa (publicados no Portal da Transparência). Foi utilizada a linguagem de Web Semântica OWL para atribuir um significado aos dados, interligando-os por meio de relações nomeadas, formando triplas que são armazenadas em triplestores, e que podem ser consultados por meio da linguagem SPARQL.

Conforme mostrado na Figura 13, a iniciativa de integração foi estruturada em cinco etapas, a saber:

1. Design e implementação da ontologia operacional a ser utilizada na iniciativa de integração. Essa versão operacional foi criada com base na ontologia de referência.

2. Extração de dados do Portal da Transparência sobre execução da despesa pública (empenhos, liquidações e pagamentos).

3. Importação dos dados extraídos do Portal da Transparência para um triplestore, usando mapeamentos baseados na ontologia operacional desenvolvida.

4. Integração dos dados importados do Portal da Transparência com os dados do SIOP. Nessa etapa é realizado um matching dos dados sobre autorização orçamentária disponibilizados pelo endpoint do SIOP com os dados sobre execução orçamentária importados no triplestore.

5. Avaliação por meio de casos de testes utilizando consultas SPARQL que refletem algumas QCs descritas no trabalho; e através de uma aplicação mobile que se conecta a uma API (Application Programming Interface) consultando diretamente os dados do triplestore. 


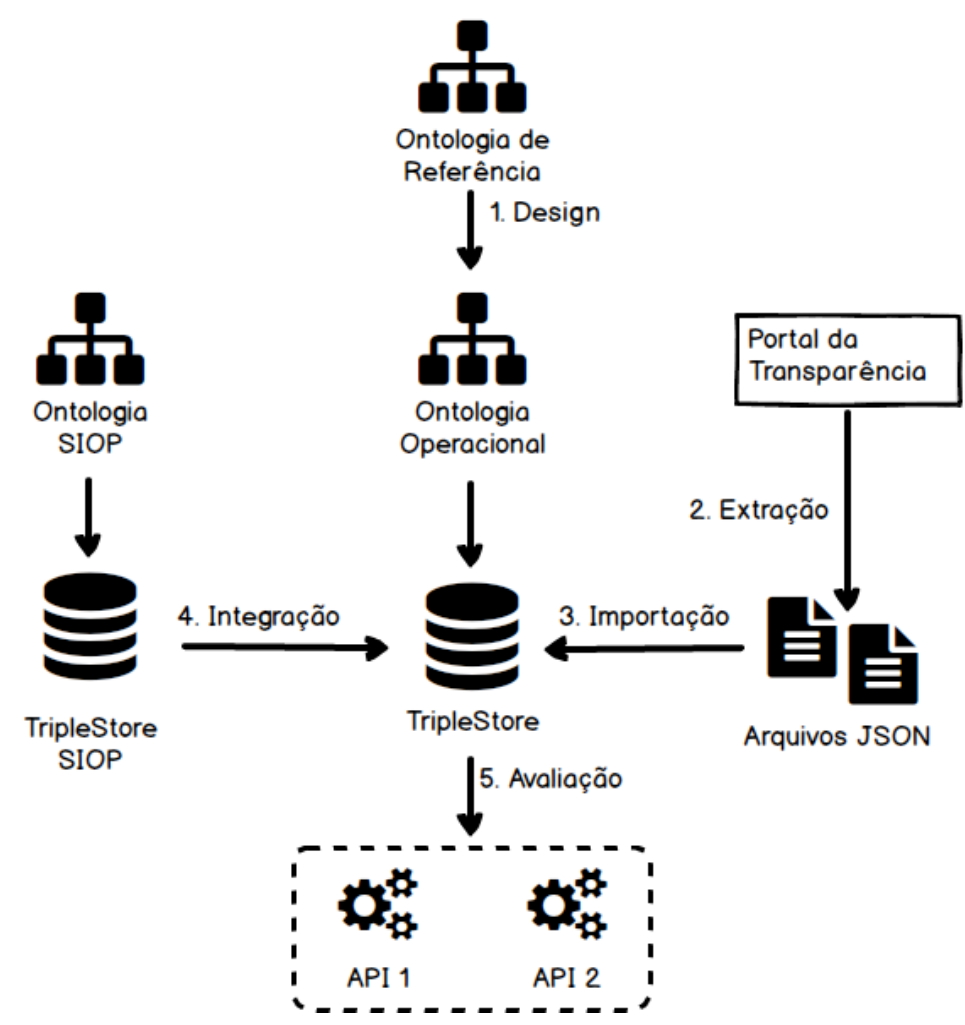

Figura 13. Etapas da Prova de Conceito

\subsection{Etapa 1: Design e Implementação da Ontologia Operacional}

Numa primeira etapa fez-se necessário desenvolver uma versão operacional da ontologia de referência, tendo-se optado pela linguagem OWL para codificá-la, correspondendo às fases de design e implementação da abordagem de Engenharia de Ontologias SABiO.

Dessa forma, para fins de design, foi considerada a necessidade de posterior integração das triplas geradas nesta etapa com os dados sobre autorização orçamentária disponibilizados pelo endpoint do SIOP (Etapa 4 desta prova de conceito), o que levou a algumas decisões de projeto a respeito da ontologia operacional.

Como mostra a Figura 14, para a subontologia de Autorização Orçamentária optou-se por omitir os conceitos que não possuem dados correspondentes disponíveis no endpoint do SIOP, a saber: Outorgante de Gasto e Orçamento (e todos os seus subtipos). Com essa alteração, Ente Federativo passa a conceder a Autorização de Despesa e a Lei Orçamentária Anual a descrever a Autorização de Despesa diretamente. Por outro lado, existem alguns dados no endpoint do SIOP que são usados na identificação de cada autorização orçamentária, mas que não possuem conceitos correspondentes contemplados no escopo na ontologia de referência (p. ex.: os dados para identificação de Programa, Ação, Função, etc.). Dessa forma, esses dados são aproveitados na ontologia operacional apenas para identificar as Autorizações de Despesas, a fim de possibilitar a integração com os dados sobre execução de despesa extraídos a partir do Portal da Transparência. Vale destacar que a ontologia operacional foi criada seguindo apenas uma direção de navegabilidade das relações, mas nada impede que a relação inversa seja criada. 


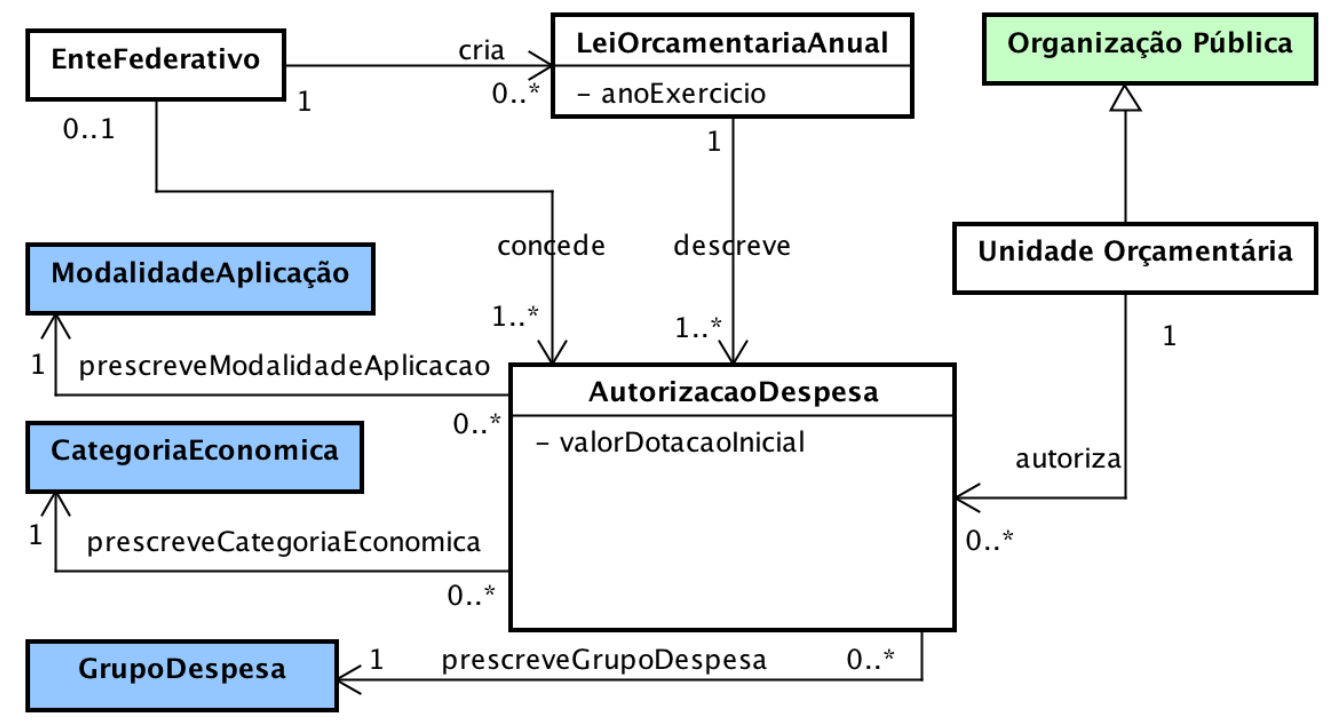

Figura 14. Modelo de Design da subontologia de Autorização Orçamentária

No projeto da subontologia de empenho, como apresentado na Figura 15, os conceitos de Material (Bem) e Tipo de Material foram omitidos por apenas aparecerem como parte do texto contido no campo "Descrição" do item empenhado, conforme explicado na subseção 5.3. A solução proposta trata indistintamente como Item de Empenho os conceitos Item de Empenho de Tipo de Material e Item de Empenho de Material, desconsiderando a especialização que conceitualmente serve para diferenciar se o item empenhado descreve um tipo de material ou um bem específico (tipo de segunda ou de primeira ordem, de acordo com MLT).

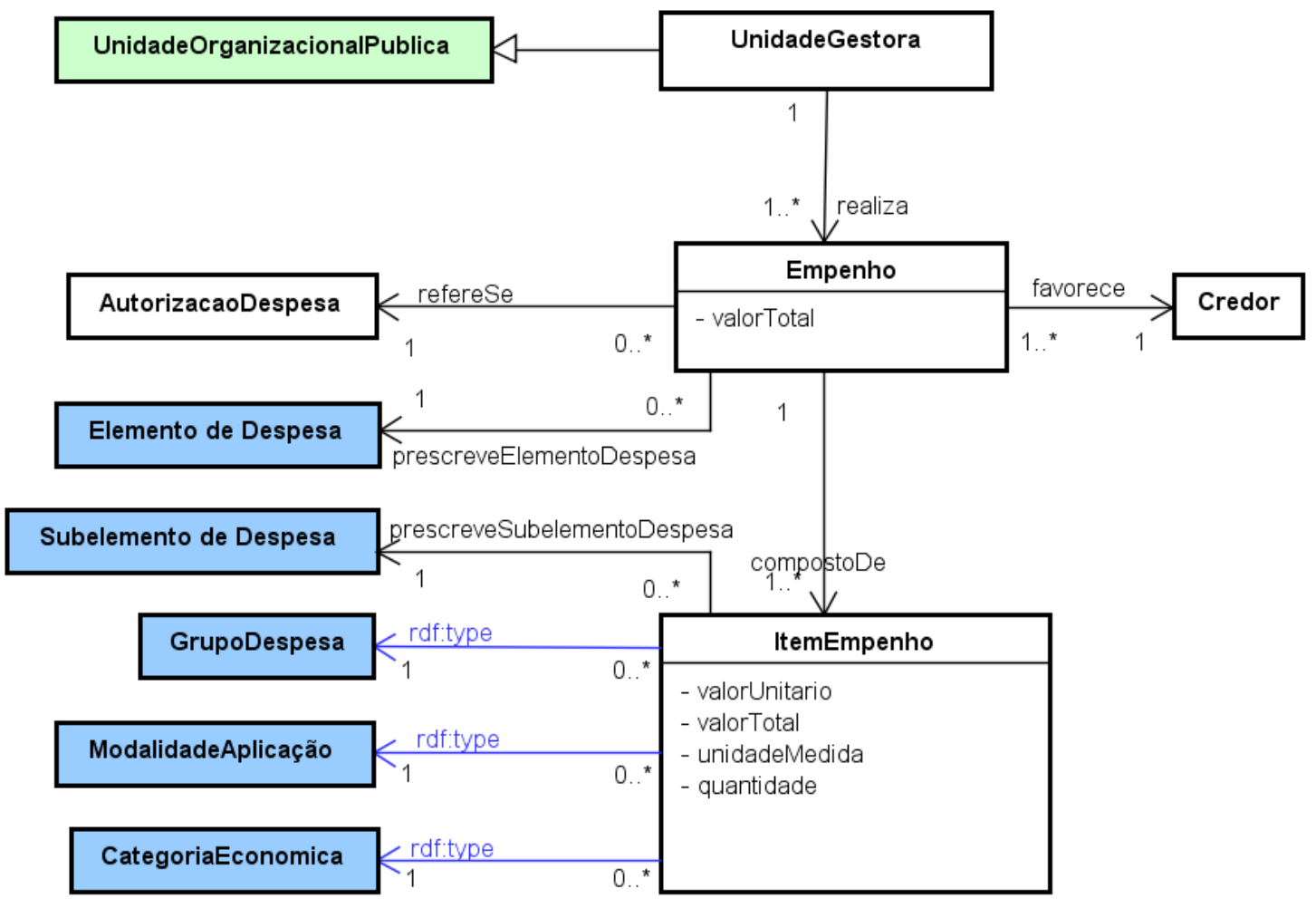

Figura 15. Modelo de Design da subontologia de Empenho 
Assim como na subontologia de empenho, nos estágios de liquidação e pagamento foi aplicado procedimento equivalente, tratando apenas os conceitos mais gerais, ou seja, Item de Liquidação e Item de Pagamento, respectivamente, como mostra a Figura 16.

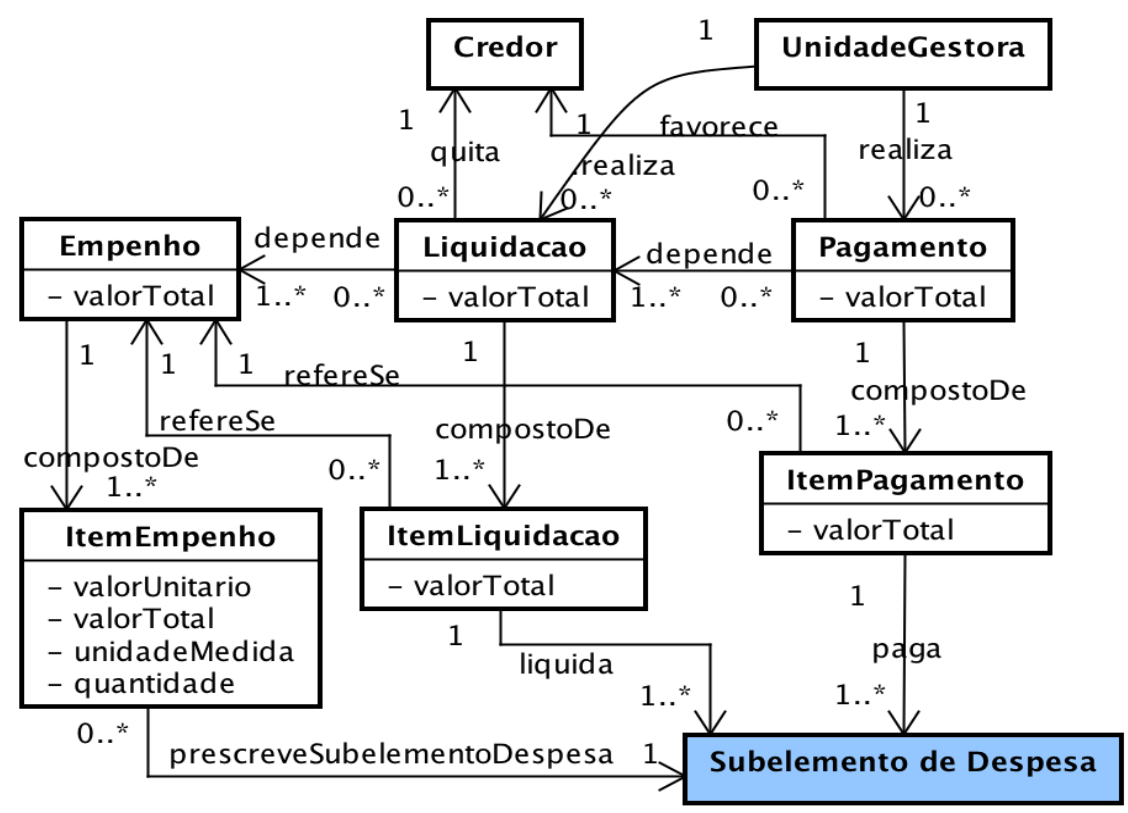

Figura 16. Modelo de Design das subontologias de Liquidação e Pagamento

\subsection{Etapa 2: Extração de Dados}

Nesta segunda etapa da iniciativa de integração de dados orçamentários, foi realizada a extração de dados referentes à execução da despesa pública. Nesta etapa foi necessário fixar alguns parâmetros a fim de se obter uma amostra de dados, a saber:

- Período: 01/01/2016 - 28/02/2016

- Órgão Superior: Ministério da Educação

- Órgão / Entidade Vinculada: Universidade Federal do Espírito Santo

Algumas dificuldades foram enfrentadas no processo de obtenção dos dados nos portais do governo federal. O Portal da Transparência, que é o principal portal do governo para disponibilização dos dados sobre empenhos, liquidações e pagamentos, possibilita apenas a realização de consultas e visualização de documentos individuais (tipicamente, das Notas de Empenho - NE; Notas de Lançamento de Sistema - NS; e Ordens Bancárias - OB). Contudo, aquele portal não disponibiliza uma opção para baixar a base de dados sobre empenhos e liquidações, possibilitando apenas o download de dados consolidados sobre pagamentos em formato CSV (Comma Separeted Values), o que dificulta a compreensão da estrutura semântica subjacente aos dados.

Devido à impossibilidade de realizar download dos dados e entendimento da sua estruturação, buscaram-se formas alternativas para obtê-los. A primeira tentativa foi usar o Sistema Eletrônico do Serviço de Informação ao Cidadão (e-SIC ${ }^{8}$ ) para solicitar os dados aos responsáveis. Foi encaminhada a amostra dos dados desejados, entretanto os

\section{" https://esic.cgu.gov.br/sistema/site/index.html}


dados foram fornecidos em formato CSV não documentado, o que impossibilitou a compreensão e o aproveitamento dos mesmos na iniciativa de integração.

Buscou-se, então, uma segunda alternativa para obtenção da amostra dos dados. Para tanto, foi desenvolvido um Web Crawler ${ }^{\circ}$ com o objetivo de rastrear as páginas, como a mostrada na Figura 17, sobre empenhos, liquidações e pagamentos do Portal de Transparência, coletando as informações desejadas e gerando arquivos em um formato processável por máquina. Como o processo foi feito na linguagem de programação JavaScript $^{10}$, optou-se por utilizar o formato JSON (JavaScript Object Notation) ${ }^{11}$.

O processo de coleta de dados por meio do Web Crawler precisou ser dividido em etapas, devido ao impedimento interposto pelo Portal da Transparência, que exigia a digitação de CAPTCHAs (Completely Automated Public Turing test to tell Computers and Humans Apart) quando a ferramenta tentava realizar várias requisições em um curto espaço de tempo no Portal. Após alguns aprimoramentos do Web Crawler, foi possível superar a dificuldade interposta pelos CAPTCHAs, viabilizando-se, assim, a obtenção dos dados necessários.

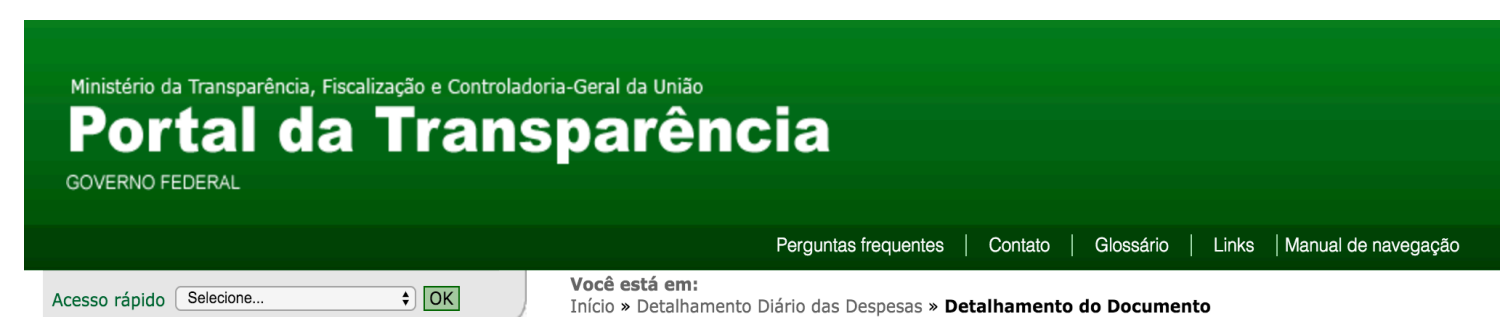

\begin{tabular}{|c|c|c|c|}
\hline \multicolumn{4}{|l|}{ DADOS BÁsICOS } \\
\hline Fase: & Empenho & & \\
\hline Documento: & 2016NE800027 & Tipo de Documento: & Nota de Empenho (NE) \\
\hline Data: & 07/01/2016 & & \\
\hline Tipo de Empenho: & ORDINARIO & Espécie de Empenho: & Original \\
\hline Órgão Superior: & 26000 - MINISTER & & \\
\hline Órgão / Entidade Vinculada: & 26234 - UNIVERSI & D ESPIRITO SANTO & \\
\hline Unidade Gestora Emitente: & 153048 - RESTAUR & A UFES & \\
\hline Gestão: & 15225 - UNIVERSI & D ESPIRITO SANTO & \\
\hline Favorecido: & $10.518 .100 / 0001-$ & SE TESCH - EPP & \\
\hline Valor: & $R \$ 8.011,04$ & & \\
\hline
\end{tabular}

Figura 17. Exemplo de página do Portal da Transparência sobre um documento de Empenho

A Listagem 1 apresenta o fragmento do arquivo JSON extraído por meio do Web Crawler do documento de empenho mostrada na Figura 17. Após a extração de dados, iniciou-se o processo de importação.

\footnotetext{
https://github.com/LucasBassetti/crawler-transparencia

${ }^{10}$ https://www.javascript.com/

"http://www.json.org/ 
Listagem 1. Fragmento do arquivo JSON de um empenho gerado pelo Web Crawler

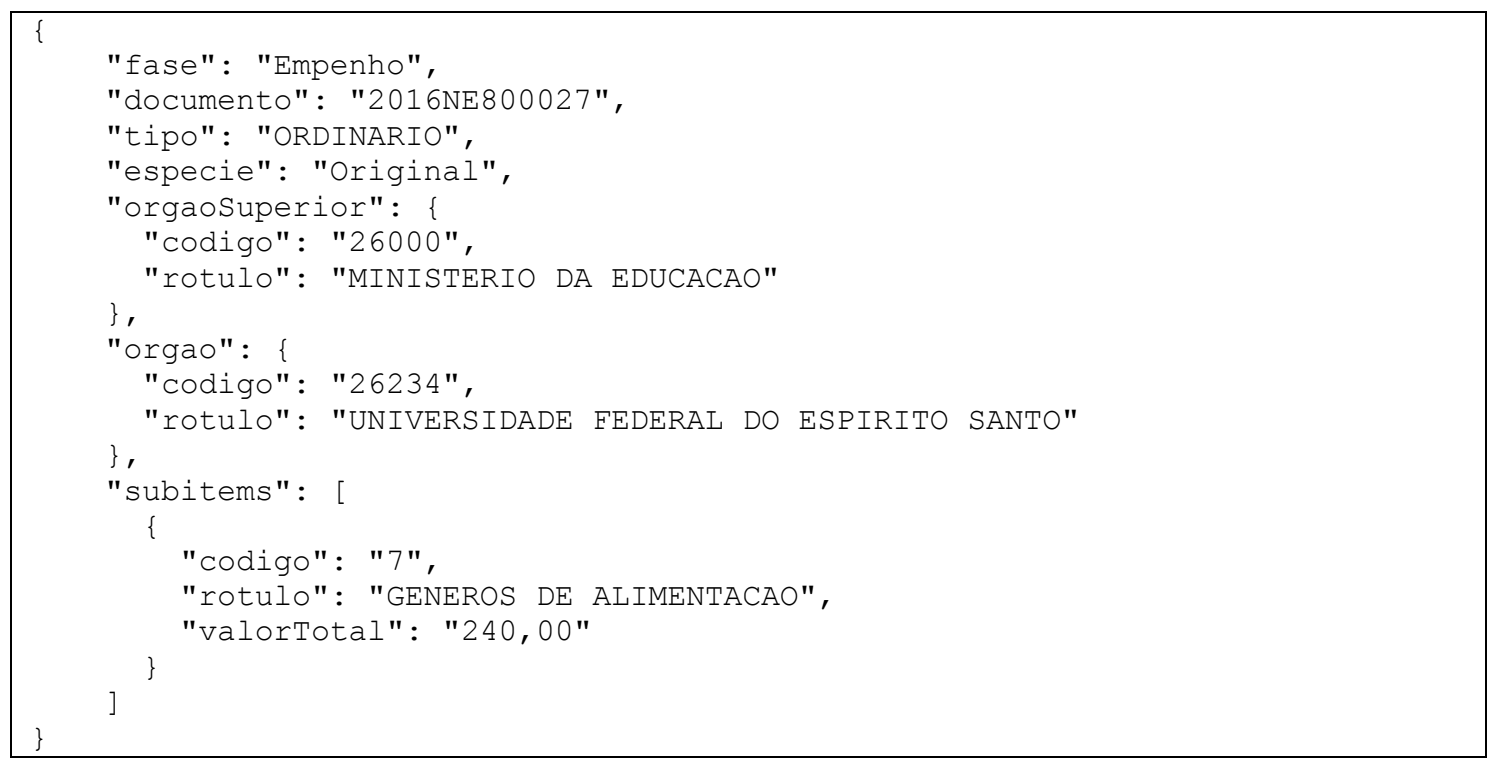

\subsection{Etapa 3: Importação dos Dados}

$\mathrm{Na}$ etapa de importação, realizou-se um mapeamento entre os dados sobre execução de despesas extraídos do Portal da Transparência e os conceitos da ontologia operacional, transformando-os em triplas (em um processo denominado triplificação). Para esse fim, um script de triplificação foi desenvolvido na linguagem de programação JavaScript ${ }^{12}$ utilizando o interpretador NodeJS ${ }^{13}$, que permite execução de código no lado do servidor. Esse script lê os arquivos JSON extraídos pelo Web Crawler, transforma os dados em triplas com base no mapeamento feito com a ontologia operacional em OWL e, por fim, insere as triplas em um triplestore (no caso, o triplestore utilizado foi o Stardog ${ }^{14}$ ).

Analisando o fragmento do documento de Empenho ${ }^{15}$ (Nota de Empenho) mostrado na Figura 18, observa-se que o detalhamento do gasto contém uma lista de subitens da despesa. Estendendo essa análise para vários documentos, notou-se que muitos subitens possuem o mesmo nome, variando apenas o texto contido em seus campos "Descrição". Dessa forma, concluiu-se que o dado apresentado no campo "Subitem da Despesa" é um tipo do que é apresentado no campo "Descrição". Realizando o mapeamento com a ontologia operacional, esse tipo representa o conceito Subelemento de Despesa que é prescrito pelo Item de Empenho.

De forma semelhante ao observado nos documentos de Empenho, tanto os documentos de Liquidação quanto os de Pagamento não explicitam qual Material (Bem) (ou Tipo de Material) está sendo liquidado ou pago. Esses documentos têm como maior nível de detalhamento apenas a indicação dos "Subitens das Despesas" (que corresponde ao conceito Subelemento de Despesa) liquidados ou pagos, respectivamente.

\footnotetext{
12 https://www.javascript.com/

${ }^{13}$ https://nodejs.org

${ }^{14}$ http://stardog.com

${ }^{15}$ http://portaltransparencia.gov.br/despesasdiarias/empenho?documento=153048152252016NE800027 


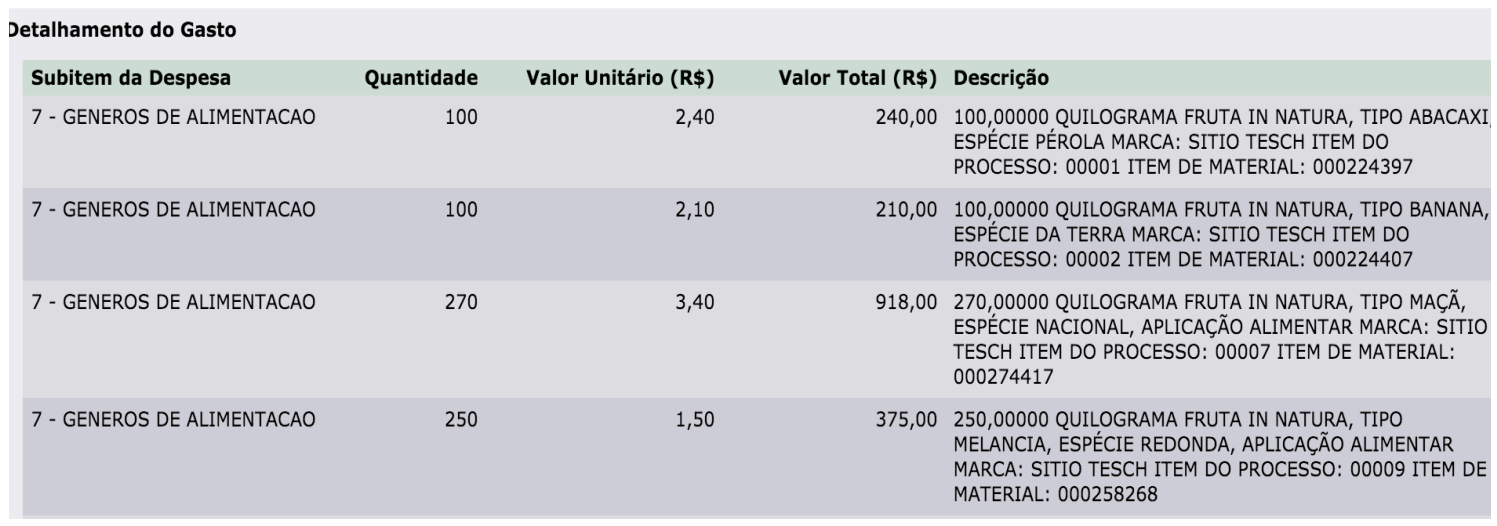

Figura 18. Fragmento do documento de Empenho sobre subitens da despesa retirado do Portal da Transparência

Seguindo o exemplo do documento de Liquidação ${ }^{16}$ da Figura 19, observa-se que, ao invés do Material(Bem) (ou Tipo de Material), cada linha liquida um "Subitem da Despesa". Isso impossibilita saber qual dos materiais (ou tipos de materiais) descritos no estágio de Empenho está sendo especificamente liquidado (ou pago, pois a mesma ideia é seguida no pagamento). Com base nessa restrição foi que se decidiu não usar os conceitos Material (Bem) e Tipo de Material da ontologia de referência na ontologia operacional. Além disso, os conceitos Item de Liquidação e Item de Pagamento passaram a ter relações diretas com o conceito Subelemento de Despesa ("Subitem da Despesa"), denominadas respectivamente "liquida" e "paga".

$\begin{array}{llllr}\text { Empenho } & \text { Subitem da Despesa } & \text { Estorno } & \text { Valor (R\$) } \\ 2015 N E 801467 & 7 \text { - GENEROS DE ALIMENTACAO } & \text { Não } & 1.633,56 \\ 2015 N E 801467 & 7 \text { - GENEROS DE ALIMENTACAO } & \text { Sim } & 1.633,56 \\ 2016 N E 800027 & 7 \text { - GENEROS DE ALIMENTACAO } & \text { Não } & 1.633,56 \\ 2016 \text { NE800027 } & 7 \text { - GENEROS DE ALIMENTACAO } & \text { Sim } & 1.633,56\end{array}$

\section{Figura 19. Fragmento do documento de Liquidação sobre subitens da despesa retirado do Portal da Transparência}

Com base no mapeamento, foi realizado o processo de triplificação dos arquivos JSON. A Figura 20 apresenta um exemplo do mapeamento da Listagem 1. Elementos na cor verde são instâncias geradas pelo conteúdo dos arquivos JSON. Cada instância representa um Uniform Resource Identifier (URI) gerado com os códigos dos classificadores orçamentários (Categoria Econômica, Grupo de Despesa, Modalidade de Aplicação, etc.). As instâncias na cor verde com bordas arredondadas são indivíduos (instanciando, portanto, tipos de primeira ordem). Instâncias na cor verde com bordas quadradas são tipos de primeira ordem (instanciando, por sua vez, tipos de segunda ordem). Já os elementos na cor amarela representam os conceitos da ontologia operacional - aqueles com bordas arredondadas são tipos de primeira ordem; e os com bordas quadradas são tipos de segunda ordem.

As relações seguem as mesmas identificações daquelas mostradas na ontologia de referência, exceto a relação de instanciação que aqui é representada pela relação $r d f$ :type de OWL. Os nomes das instâncias foram representados em OWL por rótulos (utilizando

\footnotetext{
${ }^{16}$ http://portaltransparencia.gov.br/despesasdiarias/liquidacao?documento=153048152252016NS000043 
a relação $r d f s$ :label). No entanto, os rótulos foram retirados do exemplo para não poluir a imagem. Por exemplo, a instância do SubelementoDespesa, uri-base:subelementodespesa/2016/39/7, tem o rótulo "Gêneros de Alimentação".

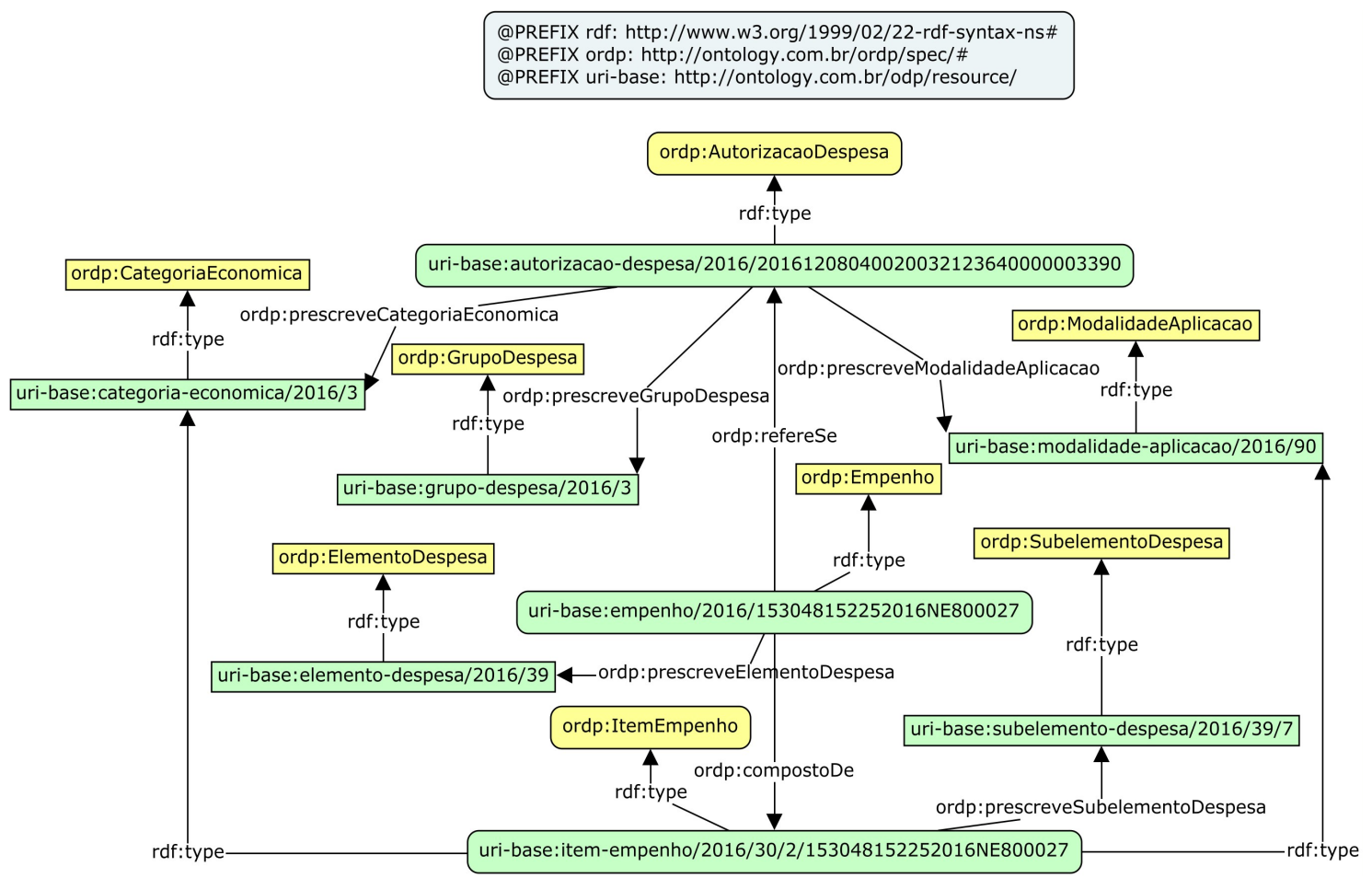

Figura 20. Exemplo de fragmento de um Empenho na forma de triplas

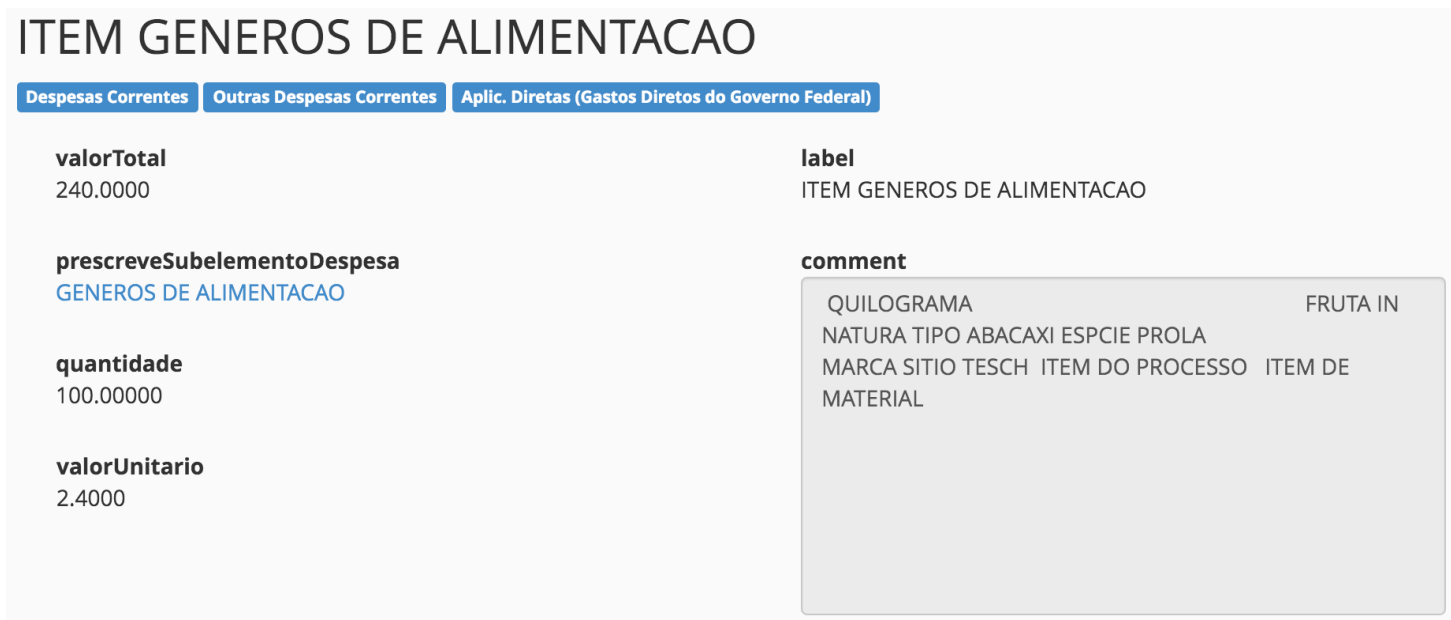

Figura 21. Exemplo de Item de Empenho

Após executar o script de triplificação, os dados foram inseridos no triplestore Stardog através de uma operação de inserção feita na linguagem SPARQL. Na Figura 21 é apresentado um fragmento dos dados triplificados no Stardog sobre a instância de Item de Empenho mostrada no exemplo da Figura 20. Pode-se verificar que a instância de Item de Empenho, prescreve a instância de Subelemento de Despesa (cujo rótulo é "Gêneros de Alimentação"), e é instância dos classificadores: Modalidade de Aplicação (rótulo "Aplic. Diretas (Gastos Diretos do Governo Federal)"); Categoria Econômica 
(rótulo "Despesas Correntes"); e Grupo de Despesa (rótulo “Outros Despesas Correntes").

Retomando o exemplo de mapeamento da Figura 20, também é possível perceber que a instância de Empenho prescreve a instância de Elemento de Despesa (no caso, "Material de Consumo") e possui uma relação refere-se a com uma instância de Autorização de Despesa. Essa relação é criada na etapa de integração, descrita na próxima seção.

\subsection{Etapa 4: Integração de Dados}

Concluída a etapa de importação, realizou-se a integração das triplas sobre execução da despesa, extraídas do Portal de Transparência, com as triplas sobre autorização orçamentária extraídas do SIOP. Os dados do SIOP usam como base o modelo ontológico de classificação das despesas do orçamento federal descrito em [SOF - Secretaria de Orçamento Federal 2013], sendo disponibilizados no formato de triplas por meio de um endpoint $^{\prime \prime}$, no qual é possível realizar consultas SPARQL, ou efetuar download de arquivos.

Assim, iniciou-se essa etapa com um matching entre os conceitos do modelo ontológico de [SOF - Secretaria de Orçamento Federal 2013] e os conceitos da ontologia operacional implementada neste trabalho, a fim de possibilitar a correlação dos dados do SIOP com esta ontologia.

Conforme discutido na Seção 6, o modelo ontológico do SIOP tem o Item de Despesa como conceito central, o qual conecta todos os classificadores orçamentários. Aos itens estão associadas propriedades que colapsam numa mesma entidade valores financeiros correspondentes a diferentes etapas (autorização orçamentária e execução da despesa) e estágios (empenho, liquidação e pagamento) dos gastos públicos, sendo os mesmos, os valores: do PLOA - Projeto de Lei Orçamentaria Anual, da LOA - Lei Orçamentária Anual (também chamado de Dotação Inicial), da LOA mais Créditos (também chamado de Dotação Atual), Empenhados, Liquidados e Pagos [SOF Secretaria de Orçamento Federal 2013].

Dessa forma, percebe-se que o modelo ontológico subjacente ao SIOP apresenta uma sobrecarga semântica para o conceito de Item de Despesa. No intuito de compreender os dados extraídos do SIOP, foram investigados alguns padrões recorrentes, buscando-se diferenciar os dados relacionados à etapa de autorização orçamentária, daqueles referentes à etapa de execução da despesa. Dessa forma, foi possível perceber que os Itens de Despesa com valor diferente de zero para a propriedade Dotação Inicial, e valores zerados para as demais propriedades, eram itens referentes à etapa de autorização (instâncias de Autorização de Despesa).

Foi possível observar, também, outro padrão no qual as propriedades de Item de Despesa que indicam os valores de empenho, liquidação e pagamento estão com valores diferentes de zero, tendo sido esses itens interpretados como se referindo à etapa de execução da despesa. 
Um exemplo contendo dados extraídos do SIOP é mostrado na Figura 22, em que o primeiro Item de Despesa é interpretado como uma instância de Autorização de Despesa e o segundo como instância de um item da execução de despesa.

\begin{tabular}{|c|c|c|}
\hline http://orcamento.dados.gov.br/id/2016/ItemDespesa/16070 & http://vocab.e.gov.br/2013/09/loa\#valorEmpenhado & 0 \\
\hline http://orcamento.dados.gov.br/id/2016/ItemDespesa/16070 & http://vocab.e.gov.br/2013/09/loa\#valorLiquidado & 0 \\
\hline http://orcamento.dados.gov.br/id/2016/ItemDespesa/16070 & http://vocab.e.gov.br/2013/09/loa\#valorDotacaoInicial & 6484391 \\
\hline http://orcamento.dados.gov.br/id/2016/ItemDespesa/16070 & http://vocab.e.gov.br/2013/09/loa\#valorProjetoLei & 0 \\
\hline http://orcamento.dados.gov.br/id/2016/ItemDespesa/16070 & http://vocab.e.gov.br/2013/09/loa\#valorPago & 0 \\
\hline http://orcamento.dados.gov.br/id/2016/ItemDespesa/78852 & http://vocab.e.gov.br/2013/09/loa\#valorEmpenhado & 31283.62 \\
\hline http://orcamento.dados.gov.br/id/2016/ItemDespesa/78852 & http://vocab.e.gov.br/2013/09/loa\#valorLiquidado & 31283.62 \\
\hline http://orcamento.dados.gov.br/id/2016/ItemDespesa/78852 & http://vocab.e.gov.br/2013/09/loa\#valorDotacaoInicial & 0 \\
\hline http://orcamento.dados.gov.br/id/2016/ItemDespesa/78852 & http://vocab.e.gov.br/2013/09/loa\#valorProjetoLei & 0 \\
\hline http://orcamento.dados.gov.br/id/2016/ItemDespesa/78852 & http://vocab.e.gov.br/2013/09/loa\#valorPago & 31283.62 \\
\hline
\end{tabular}

Figura 22. Exemplo de Sobrecarga Semântica - Item de Despesa com significados distintos nos dados extraídos do SIOP

Seguindo essa interpretação, foram realizados os mapeamentos dos Itens de Despesa (extraídos do SIOP) cujo valor da dotação inicial fosse maior que zero como uma Autorização de Despesa da versão operacional de ORDP. Para esse fim, foi desenvolvido um script para associar (usando a relação owl:sameAs) as Autorizações de Despesa com os Itens de Despesa do SIOP que possuíam os mesmos classificadores orçamentários, ou seja, ambos indicavam o mesmo Órgão, Unidade Orçamentária, Categoria Econômica, Modalidade de Aplicação, Grupo de Despesa, etc. A Figura 23 apresenta um exemplo de instância de Autorização de Despesa ligada a uma instância de Item de Despesa por meio da relação owl:sameAs, indicando que na realidade ambas retratam um mesmo indivíduo.

\section{Autorização da Despesa 20161208040020032123640000003390 \\ prescreveCategoriaEconomica \\ Despesas Correntes \\ prescreveModalidadeAplicacao \\ Aplic. Diretas (Gastos Diretos do Governo Federal) \\ label \\ Autorização da Despesa 20161208040020032123640000003390 \\ sameAs \\ http://orcamento.dados.gov.br/id/2016/ItemDespesa/3988}

prescreveGrupoDespesa

Outras Despesas Correntes

Figura 23. Exemplo de integração entre uma Autorização de Despesa com um Item de Despesa do SIOP

\subsection{Etapa 5: Avaliação}

Esta seção apresenta a demonstração feita para mostrar a capacidade de ORDP apoiar a integração de dados orçamentários, iniciando com o design e execução de casos de teste para as QCs e finalizando com uma aplicação mobile que consome os dados através de queries SPARQL. 


\subsubsection{Casos de teste}

Uma vez integrados os dados, realizaram-se inicialmente casos de teste por meio de consultas SPARQL que refletem as QCs descritas no trabalho. O objetivo é avaliar a ontologia através de consultas sobre dados reais que cruzem todo o seu escopo.

Entre as principais QCs, encontram-se as questões que requerem integração dos dados, ou seja, que envolvem tanto dados da etapa de autorização orçamentária, quanto da etapa de execução de despesas. Elas permitem rastrear, por exemplo, qual foi a autorização orçamentária presente na LOA que autorizou determinado pagamento, ou quais unidades gestoras empenharam recursos de determinada autorização. Para exemplificar este caso, a Tabela 7 apresenta dois exemplos de QCs com suas respectivas consultas SPARQL, em que a variável "autorizaçãoDespesa" assume o valor $<$ http://ontology.com.br/odp/resource/autorizacao-despesa/2016/

20161208020GK0032123645000003390>.

Tabela 7. Consultas SPARQL e resultados dos respectivos casos de teste

\begin{tabular}{|c|c|}
\hline QC10 & $\begin{array}{l}\text { Quais unidades gestoras empenharam recursos de uma determinada } \\
\text { autorização de despesa? }\end{array}$ \\
\hline SPARQL & $\begin{array}{l}\text { SELECT DISTINCT ?unidadeGestora WHERE \{ } \\
\text { ?unidadeGestoraURI ordp:realiza ?empenho; } \\
\text { rdfs: label ?unidadeGestora. } \\
\text { ?empenho a ordp: Empenho; } \\
\text { ordp:refereSe ?autorizacaoDespesa . } \\
\text { \} }\end{array}$ \\
\hline \multirow{2}{*}{ Resultado } & unidadeGestora \\
\hline & UNIVERSIDADE FEDERAL DO ESPIRITO SANTO \\
\hline QC27 & $\begin{array}{l}\text { Quanto do valor de uma determinada autorização de despesa foi } \\
\text { efetivamente objeto de pagamentos? }\end{array}$ \\
\hline SPARQL & $\begin{array}{l}\text { SELECT } \\
\text { (SUM(xsd:double(?valorTotalAD)) as ?valorAD) } \\
\text { (SUM(xsd:double(?valorTotalPago)) as ?valorPago) } \\
\text { WHERE \{ } \\
\text { ?pagamento rdf:type ordp:Pagamento; } \\
\text { ordp:depende ?empenho ; } \\
\text { ordp:valorTotal ?valorTotalPago . } \\
\text { ?empenho rdf:type ordp:Empenho; } \\
\text { ordp:refereSe ?autorizacaoDespesa. } \\
\text { ?autorizacaoDespesa ordp:valorDotacaoInicial ?valorTotalAD . } \\
\text { \} }\end{array}$ \\
\hline \multirow[t]{2}{*}{ Resultado } & valorPago \\
\hline & $R \$ 12.968 .782,00$ \\
\hline
\end{tabular}

As demais QCs, assim como a ontologia operacional (em OWL), estão disponíveis no repositório do GitHub ${ }^{18}$ para consulta. O repositório também apresenta um link para um SPARQL endpoint, em que é possível testar as QCs com a amostra dos dados obtidos.

\footnotetext{
"s https://github.com/LucasBassetti/despesa-orcamentaria 


\subsubsection{Aplicação Mobile de Consumo dos Dados Obtidos}

Uma vantagem dos dados triplificados é a possibilidade de se realizar diferentes consultas interligando diversas informações do grafo de triplas. Além disso, é possível transformar essas consultas em funções de uma API (Interfaces de Programação de Aplicativos), ou seja, através dos dados triplificados é possível gerar uma variedade de APIs que manipulem esses dados de diferentes formas.

Como demonstração desta capacidade viabilizada pela abordagem utilizada neste trabalho, foi desenvolvida uma API ${ }^{19}$ em NodeJS com duas funções: (i) uma função que busca o número de empenhos por credores; e (ii) uma função que busca detalhes de um credor com número e valor total de empenhos e pagamentos.

Foi desenvolvida uma aplicação mobile ${ }^{20}$ para apresentar os dados a partir das funções da API. A aplicação possui duas telas principais, como mostra a Figura 24. A tela da esquerda apresenta a lista de credores ordenados pelo número de empenhos, sendo que, ao selecionar um credor, a aplicação apresenta a tela da direita detalhando o número de pagamentos e o valor total empenhado e pago.

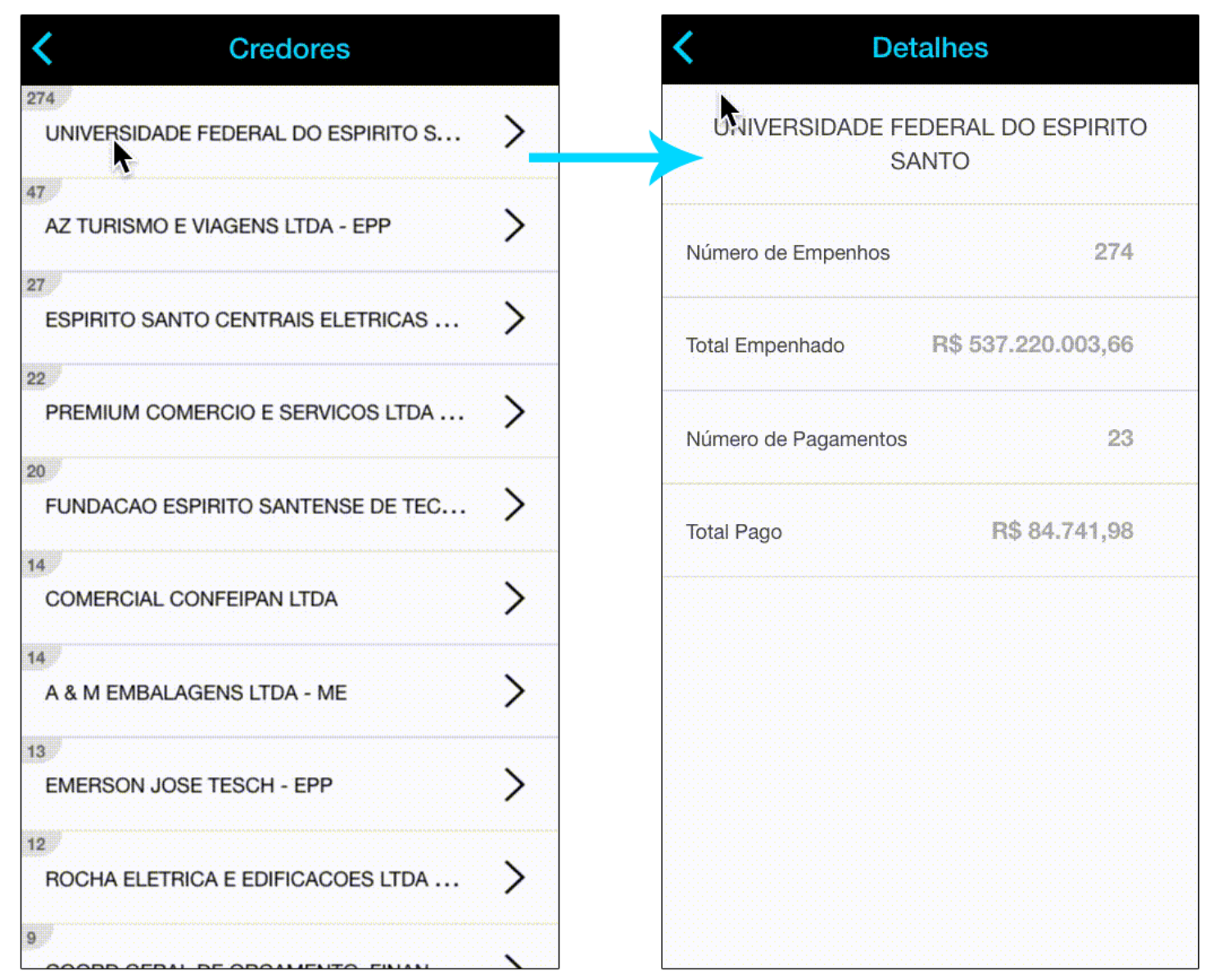

Figura 24. Exemplo de aplicação usando os dados triplificados.

\footnotetext{
${ }^{19}$ https://github.com/LucasBassetti/despesa-orcamentaria/tree/master/api

${ }_{20}^{2}$ https://github.com/LucasBassetti/despesa-orcamentaria/tree/master/loa-app

iSys: Revista Brasileira de Sistemas de Informação (iSys: Brazilian Journal of Information Systems) http://seer.unirio.br/index.php/isys/
} 


\section{Trabalhos Correlatos}

Conforme mencionado anteriormente, existem outras iniciativas de construção de ontologias para domínios correlatos ao abordado neste trabalho. Algumas delas foram desenvolvidas com participação de atores do próprio governo federal brasileiro, como as encontradas no portal do e-VoG. Uma das ontologias existentes no portal é o modelo ontológico de classificação das despesas do orçamento federal brasileiro, o qual foi inicialmente descrito por [Araújo, L. S. O. et al. 2012], e cuja versão mais atual encontrase publicada em [SOF - Secretaria de Orçamento Federal 2013], conforme apontado em [Araújo et al., 2015]. A Figura 25 mostra uma versão desse modelo ontológico em que os principais conceitos são o item de despesa e seus classificadores orçamentários.

A ontologia apresentada em [SOF - Secretaria de Orçamento Federal 2013] é do tipo operacional e seu escopo é a autorização e acompanhamento orçamentária a partir da LOA, subsidiando dados do SIOP, e portanto, diferentemente de ORDP, não são considerados conceitos presentes nos estágios de execução da despesa (p.ex.: Credor, Subelemento da Despesa, Empenho, Liquidação e Pagamento), tratando as informações oriundas daqueles estágios apenas de forma consolidada em valores numéricos (na versão do modelo apresentado na Figura 25 estão ausentes as entidades loa:valorEmpenhado, loa:valorLiquidado e loa:valorPago, que fazem parte da versão mais atual). Como consequência, a granularidade da conceituação sobre despesas é menos fina, e, além disso, há o problema de uma entidade (Item Despesa) estar sobrecarregada com propriedades que deveriam pertencer a conceitos diferentes. Por exemplo, para um item autorizado no orçamento, o modelo prevê apenas a possibilidade de se conhecer, a partir do valor orçamentário autorizado para gasto com este item, o quantitativo orçamentário comprometido na execução (valor empenhado), ou o quantitativo financeiro pago, não sendo representado, por exemplo, o credor (pessoa ou empresa) que recebeu o recurso público. Portanto, aquele modelo não se ocupa em retratar conceitos envolvidos na efetiva execução da despesa pública.

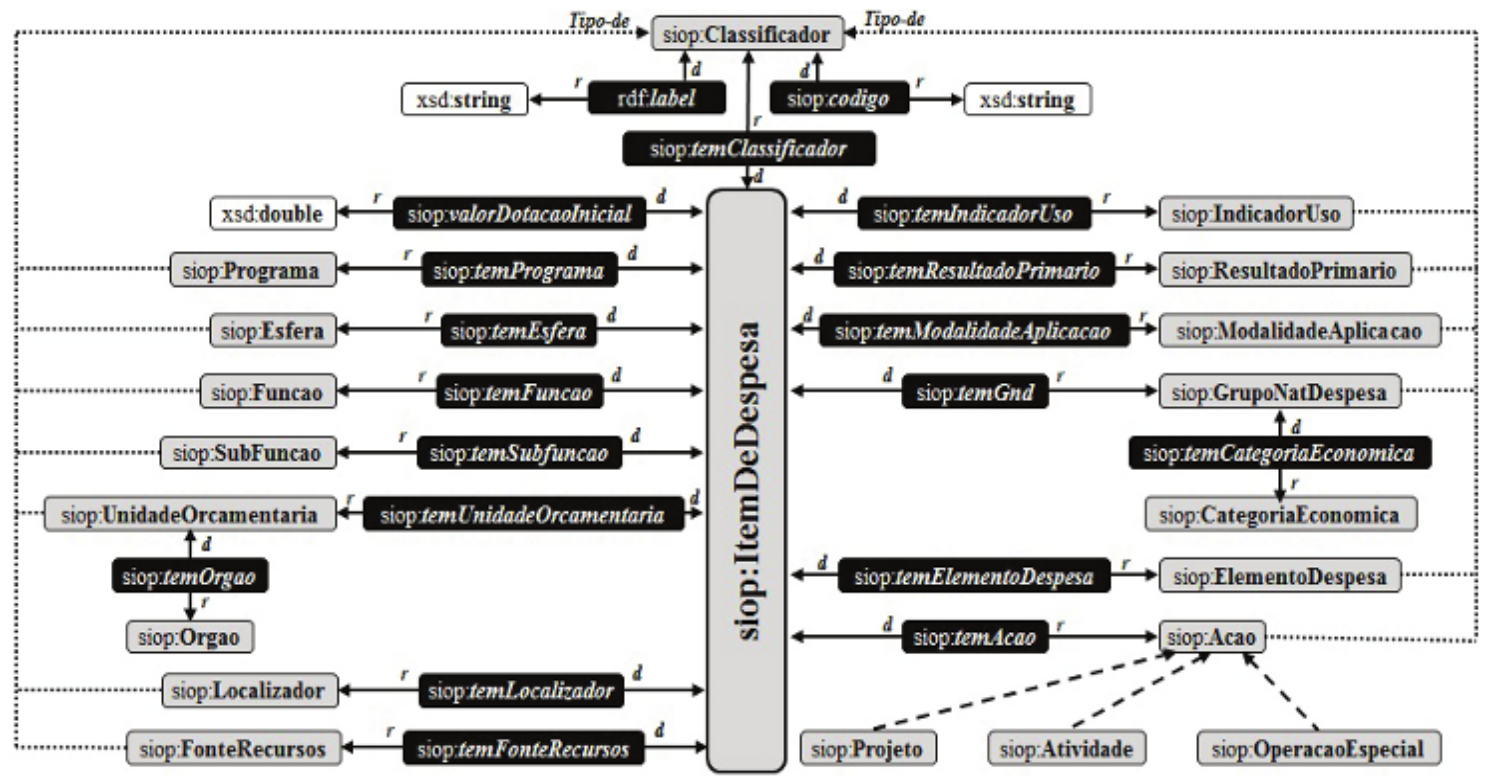

Figura 25. Ontologia de Classificação da Despesa Orçamentária Federal [SOF Secretaria de Orçamento Federal 2013] 
Vale destacar, ainda, outra diferença conceitual existente entre a entidade Item de Despesa (siop:ItemDeDespesa) apresentada em [SOF - Secretaria de Orçamento Federal 2013], e o conceito Autorização de Despesa da ORDP. Em [SOF - Secretaria de Orçamento Federal 2013], apesar de Item de Despesa ser a entidade central, conectando todos os classificadores, ela é tratada na ontologia como "sem correspondência", pois, de acordo com os autores não existe conceito correspondente no Manual Técnico do Orçamento. Todavia, a ORDP se ocupa em apresentar uma semântica para este conceito central no orçamento, a Autorização de Despesa, em que instâncias deste conceito são relators sociais que autorizam a execução das despesas públicas.

Ademais, fica evidente que a preocupação da ontologia apresentada em [SOF Secretaria de Orçamento Federal 2013] é apenas de expor os dados na Web em conformidade com os princípios dos Dados Ligados (Linked Data) [Bizer et al. 2009] (uma melhoria em relação aos formatos utilizados anteriormente, como CSV e PDF). Contudo, aquele modelo não se detém em aprofundar a semântica dos conceitos envolvidos e suas relações, o que é um aspecto chave de ORDP.

Outra iniciativa é apresentada por [Martins et al. 2013], que descreve uma ontologia para o orçamento público federal criada utilizando o método Deronto [Caliari 2007]. Este método consiste na construção de ontologias a partir de diagramas de entidade-relacionamento (apesar disso os diagramas não são apresentados em detalhes por [Martins et al. 2013]). A ontologia propõe tanto a classificação da receita, quanto da despesa orçamentária. Apesar do método utilizado na construção dessa ontologia indicar a possibilidade de criação de modelos de referência uma maior precisão semântica, em [Martins et al. 2013] não há preocupação com uma descrição precisa das relações entre as entidades, nem é apresentada a axiomatização da ontologia proposta. Isso se deve, possivelmente, ao foco daquele trabalho no desenvolvimento e avaliação de uma ontologia operacional. O escopo dessa ontologia, apesar de englobar a receita orçamentária, diferentemente da ORDP, não detalha o processo da execução da receita e despesa, assim como em [SOF - Secretaria de Orçamento Federal 2013], não havendo preocupação em identificar e definir precisamente as relações e papéis envolvidos em cada etapa dos processos de autorização orçamentária e de execução da despesa.

A Tabela 8 aponta as principais diferenças entre a ORDP e as demais ontologias apresentadas nesta seção.

\section{Conclusão}

Dado o interesse do cidadão na transparência do gasto público, uma grande parte dos dados disponibilizados refere-se justamente ao orçamento e às despesas, o que, em princípio, dá ao cidadão o poder de acessar e fiscalizar os gastos públicos, auxiliando no combate à corrupção e na melhoria da efetividade dos gastos governamentais. Não obstante, há empecilhos para o consumo e ligação dos dados disponibilizados por estes portais. Este trabalho objetiva mitigar estes empecilhos com o emprego de uma ontologia de referência para as etapas de autorização orçamentária e execução da despesa pública federal. Foi demonstrado como a ontologia de referência pode ser usada na integração de dados de fontes heterogêneas e sua posterior disponibilização para consumo através de técnicas da Web Semântica. 
Tabela 8. Diferenças entre ORDP e trabalhos correlatos

\begin{tabular}{|c|c|c|}
\hline ORDP & $\begin{array}{c}\text { Ontologia da Despesa do } \\
\text { Orçamento Federal [SOF - } \\
\text { Secretaria de Orçamento } \\
\text { Federal 2013] }\end{array}$ & $\begin{array}{c}\text { Ontologia para o } \\
\text { Orçamento Público } \\
\text { Federal [Martins et al. } \\
\text { 2013] }\end{array}$ \\
\hline $\begin{array}{l}\text { - Ontologia de referência } \\
\text { - Método: SABiO } \\
\text { - Maior precisão semântica } \\
\text { de conceitos e relações } \\
\text { - Escopo: autorização de } \\
\text { despesa orçamentária e } \\
\text { execução da despesa } \\
\text { pública (empenho, } \\
\text { liquidação e pagamento) } \\
\text { - Principais conceitos } \\
\text { definidos: "Autorização } \\
\text { de Despesa", "Empenho", } \\
\text { "Liquidação" e } \\
\text { "Pagamento" }\end{array}$ & $\begin{array}{l}\text { - Ontologia operacional } \\
\text { - Método: não identificado } \\
\text { - Uso de princípios de } \\
\text { Linked Data para } \\
\text { publicação de dados na } \\
\text { Web } \\
\text { - Escopo: autorização e } \\
\text { acompanhamento de } \\
\text { despesa orçamentária } \\
\\
\text { - Principal conceito } \\
\text { definido: } \\
\text { "ItemDeDespesa" - } \\
\text { entidade sobrecarregada } \\
\text { (polissemia) }\end{array}$ & $\begin{array}{l}\text { - Ontologia operacional. } \\
\text { - Método: Deronto } \\
\text { - Precisão semântica } \\
\text { restrita a aquisição de } \\
\text { conhecimentos a partir de } \\
\text { diagramas ER. } \\
\text { - Escopo: autorização e } \\
\text { acompanhamento de } \\
\text { receita e despesa } \\
\text { orçamentárias } \\
\text { - Principais conceitos } \\
\text { definidos: "Orçamento", } \\
\text { "Receita" e "Despesa". }\end{array}$ \\
\hline
\end{tabular}

O estudo nos permite propor aprimoramentos para integração dos dados publicados pelo governo federal sobre as etapas de autorização orçamentária e execução de despesas públicas e, assim, facilitar a compreensão e o processamento desses dados.

Primeiramente, percebeu-se que o SIAFI é administrado no âmbito do Ministério da Fazenda, porém a divulgação dos seus dados (sobre a execução de despesas públicas) ocorre através do Portal da Transparência do Governo Federal, o qual é administrado por um órgão vinculado a outro ministério, a Controladoria Geral da União. Por outro lado, o SIOP é mantido pelo Ministério do Planejamento, Orçamento e Gestão, o qual também é responsável pelo portal de divulgação dos dados sobre autorização orçamentária. Isto pode estar na raiz de alguns problemas de integração identificados neste trabalho.

Mais especificamente, no caso do SIOP, existe a iniciativa de um modelo ontológico de classificação das despesas do orçamento federal brasileiro, descrita em [SOF - Secretaria de Orçamento Federal 2013] e apresentada na seção sobre trabalhos correlatos, tendo-se destacado algumas diferenças conceituais existentes entre aquele modelo ontológico e ORDP. Neste sentido, o uso do conceito de relator teve um papel central para expressar aspectos semânticos das entidades envolvidas, uma vez que a autorização orçamentária e a execução de despesas podem ser compreendidas como relações sociais, que se desdobram em uma cadeia de dependências ao longo do processo, envolvendo diferentes atores que desempenham diferentes papéis.

Já no caso do Portal da Transparência (ou mesmo o SIAFI), inexiste uma ontologia subjacente aos dados divulgados (ou ao menos não há divulgação dessa ontologia), a fim de permitir uma melhor compreensão dos dados publicados, assim como sua integração com outras fontes de dados. Diferentemente do SIOP, não há endpoint em que seja possível realizar consultas ou realizar download de arquivos contendo os dados sobre execução de despesas públicas no formato de triplas seguindo o padrão W3C para 
intercâmbio de dados na Web, que possibilitaria uma integração mais simples com outras fontes de dados.

Por fim, percebe-se uma limitação quanto à granularidade da informação capturada pelo SIAFI na etapa de execução de despesas, haja vista que o conceito Material (Bem), ou Tipo de Material, fica apenas subentendido como parte do texto que descreve (campo "Descrição") um Item de Empenho, ou seja, esse conceito não é capturado pelo sistema. Dessa forma, nos casos em que o Empenho é composto por vários Itens de Empenho que prescrevam um mesmo tipo de Subelemento de Despesa (como é o caso do exemplo mostrado Figura 18), o sistema não permite saber, nos estágios de liquidação e pagamento, qual desses Itens de Empenho (e, por conseguinte, qual Material (Bem)) está sendo efetivamente liquidado ou pago. Ou seja, não é possível saber, pelo sistema, se estão sendo liquidados (ou pagos) os abacaxis ou as maçãs que foram objetos de um mesmo Empenho (para isso seria necessário ter acesso ao documento fiscal que originou a liquidação).

Por se tratar de um domínio muito amplo e complexo, entende-se que, para representá-lo, o desenvolvimento da ontologia de referência deve ser realizado de forma iterativa e incremental, conforme propõe [Falbo 2014]. Para a versão da ORDP apresentada neste artigo, decidiu-se por uma cobertura parcial do domínio, vislumbrando o futuro desenvolvimento de uma rede de ontologias [Suárez-Figueroa et al. 2012], em que a ORDP pode ser vista como um embrião para essa rede. Dessa forma, na estruturação da rede deverão ser acrescentadas outras ontologias interligadas de forma consistente, que compartilharão conceitos e relações, a fim de ampliar a abrangência conceitual da ontologia. Nesse sentido, para composição da rede de ontologias, alguns aspectos poderão ser generalizados (p.ex., execução de despesas públicas) para uma ontologia de nível mais genérico (ontologia core) e posteriormente especializados para outros tipos de despesas em ontologias mais específicas (p.ex., ontologias de domínio para representar a contratação de serviços, aposentadorias e pensões).

Nesse sentido, podem ser citados como potenciais trabalhos futuros: (i) Aprofundar o modelo sobre autorização orçamentária de forma a explorar com mais detalhes a semântica dos classificadores orçamentários, ampliando o escopo da ontologia para abranger conceitos de outras classificações orçamentárias, tais como a funcional e, principalmente a classificação programática a partir de pesquisas sobre os conceitos inerentes ao PPA e à LDO, assim como as inter-relações desses conceitos com aqueles apresentados aqui sobre a LOA; (ii) Estudar a inclusão de conceitos que contemplem despesas públicas diversas daquelas modeladas neste trabalho (que foram as despesas com aquisição de materiais de consumo e permanentes, ou bens); (iii) Explorar a ontologia nas três esferas (federal, estadual e municipal) para que ela possa ser facilmente intercambiável entre essas esferas, servindo como um modelo genérico; (iv) Expandir a ontologia com outros domínios do governo (p.ex.: Receita Orçamentária, Gestão de Convênios da Administração Pública, etc.), buscando uma padronização e estruturação dos dados públicos, melhorando a confiabilidade da informação, além da integração e consumo dos dados; (v) Aumentar a quantidade de dados utilizados na integração para testar as consultas com outros órgãos e credores, e para verificar o comportamento em relação ao tempo de resposta dos resultados. 


\section{Agradecimentos}

O presente trabalho foi realizado com o apoio da Coordenação de Aperfeiçoamento de Pessoal de Nível Superior - Brasil (CAPES) - Código de Financiamento 001, do CNPq (312123/2017-5, 407235/2017-5) e da FAPES (69382549).

\section{Referências}

Araújo, L. S. de O. Silva, D. A. Santos, M. T. et al. (2012) "Uma Ontologia das Classificações da Despesa do Orçamento Federal", In: CEUR Workshop Proceedings, http://ceur-ws.org/Vol-938/ontobras-most2012 paper30.pdf, Fevereiro/2019.

Berners-Lee, T. Hendler, J. e Lassila, O. (2001) "The Semantic Web", In: Scientific American, v. 284, n. 5, p. 28-37.

Bizer, C. Heath, T. e Berners-Lee, T. (2009) "Linked Data - The Story So Far", In: International journal on semantic web and information systems, v. 5, n. 3, p. 1-22.

Brasileiro, F. Almeida, J. P. A. Carvalho, V. A. e Guizzardi, G. (2016) "Applying a MultiLevel Modeling Theory to Assess Taxonomic Hierarchies in Wikidata", In: Wiki Workshop 2016 at 25th Int. Conference Companion on World Wide Web, p. 975-980.

Caliari, F. M. (2007), "Deronto: Método para Construção de Ontologias a partir de Diagramas de Entidade-Relacionamento", Universidade Técnológica Federal do Paraná, Pós-Graduação em Engenharia Elétrica e Informática Industrial, Dissertação Mestrado.

Câmara dos Deputados (2016) "LOA 2016 - Redação Final", In Portal da Câmara dos Deputados, http://www2.camara.leg.br/orcamento-da-uniao/leis-orcamentarias/loa/ 2016/texto-da-lei/loa2016, Fevereiro/2019.

Carvalho, V. A. e Almeida, J. P. A. (2015) "A Semantic Foundation for Organizational Structures: A Multi-level Approach", In: 2015 IEEE 19th International Enterprise Distributed Object Computing Conference, p. 50-59.

Carvalho, V. A. Almeida, J. P. A. Fonseca, C. M. e Guizzardi, G. (2015) "Extending the Foundations of Ontology-based Conceptual Modeling with a Multi-Level Theory", In: 34rd International Conference on Conceptual Modeling (ER2015).

Carvalho, V. A. Almeida, J. P. A. e Guizzardi, G. (2016) "Using a Well-Founded MultiLevel Theory to Support the Analysis and Representation of the Powertype Pattern in Conceptual Modeling", In: 28th Intl. Conf. on Advandced Information Systems Engineering.

Carvalho, V. A. Almeida, J. P. A. (2016) "Towards a Well-Founded Theory for MultiLevel Conceptual Modelling", In: Int. J. Softw. Syst. Model.

Charalabidis, Y. Lampathaki, F. Kavalaki, A. e Askounis, D. (2010) "A review of electronic government interoperability frameworks: patterns and challenges", In: International Journal of Electronic Governance, v. 3, n. 2, p. 189-221.

Craveiro, G. da S. Santana, M. T. e Albuquerque, J. P. (2013) "Assessing Open Government Budgetary Data in Brazil", In: ICDS 2013, The Seventh International Conference on Digital Society.

Falbo, R. A. (2014) "SABiO: Systematic Approach for Building Ontologies An Overview of SABiO", In: 1st Joint Workshop Onto.Com/ODISE on Ontologies in Conceptual Modeling and Information Systems Engineering.

Falbo, R. A. Barcellos, M. P. Nardi, J. C. e Guizzardi, G. (2013) "Organizing Ontology 
Design Patterns as Ontology Pattern Languages", In: 10th Extended Semantic Web Conference, Montpellier, France.

Fonseca, L. B. R. Azevedo, C. L. B. e Almeida, J. P. A. (2014) "Mapeando Dados Governamentais com uma Ontologia de Organizações" In: LOD Brasil, Linked Open Data.

Fonseca, L. B. R. Detoni, A. A. Almeida, J. P. A. e Falbo, R. D. A. (2016) "Uma Proposta de Ontologia de Referência para Autorização Orçamentária e Execução da Despesa Pública", In: Ontobras 2016.

Giacomoni, J. (2010), Orçamento Público, Atlas, 15ª ed. São Paulo.

Griffo, C. Almeida, J. P. A. e Guizzardi, G. (2015) "Towards a Legal Core Ontology based on Alexy' s Theory of Fundamental Rights", In: Multilingual Workshop on Artificial Intelligence and Law, ICAIL 2015.

Guarino, N. e Guizzardi, G. (2015) "We Need to Discuss the Relationship: Revisiting Relationships as Modeling Constructs", In: Advanced Information Systems Engineering. . Springer International Publishing.

Guarino, N. Staab, S. e Studer, R. (2009), Handbook on Ontologies, Springer Berlin Heidelberg, $2^{\text {nd }}$ edition, Berlin.

Guizzardi, G. (2005), Ontological Foundations for Structural Conceptual Model, CTIT Centre for Telematics and Information Technology, University of Twente, Doctoral Thesis.

Guizzardi, G. (2007) "On Ontology, ontologies, Conceptualizations, Modeling Languages, and (Meta)Models", In: Frontiers in Artificial Intelligence and Applications, Databases and Information Systems IV, v. 155, p. 18-39.

Guizzardi, G. Falbo, R. e Guizzardi, R. S. S. (2008) "Grounding Software Domain Ontologies in the Unified Foundational Ontology ( UFO ): The case of the ODE Software Process Ontology", In: CIbSE, p. 127-140.

Harris, S. e Seaborne, A. (2013) "SPARQL 1.1 Query Language", W3C recommendation, v. 21, n. 10 .

Hevner, A. e Chatterjee, S. (2010), "Design science research in information systems", In: Design research in information systems, Springer US, p. 9-22.

Martins, L. C. Craveiro, G. S. e Alcázar, J. de J. (2013) "Definição e Validação de uma Ontologia para o Orçamento Público Federal Brasileiro (v.1.0)", In:Relatório Técnico PPgSI-002/2013.

McGuinness, D. L. e Harmelen, F. Van (2004), OWL Web Ontology Language Overview, W3C recommendation, v. 10.

Ministério do Planejamento, Desenvolvimento e Gestão (2011) "Esboço de Modelagem Conceitual para Estruturas Organizacionais Governamentais Brasileiras e o SIORG", http://vocab.e.gov.br/2011/09/org, Fevereiro/2019.

Ministério do Planejamento, Desenvolvimento e Gestão (2016) "MTO 2016 - Manual Técnico do Orçamento", http://www.orcamentofederal.gov.br/informacoesorcamentarias/manual-tecnico/mto 2016 2aedicao 220915.pdf, Fevereiro/2019.

Nardi, J. C. Falbo, R. A. e Almeida, J. P. A. (2013) "A panorama of the semantic EAI initiatives and the adoption of ontologies by these initiatives", In: 5th International IFIP Working Conference on Enterprise Interoperability (IWEI 2013). 
Nardi, J. C. Falbo, R. A. Almeida, J. P. A. et al. (2013) "Towards a Commitment-based Reference Ontology for Services", In: Enterprise Distributed Object Computing Conference (EDOC), 17th IEEE International, p. 175-184.

Nunamaker Jr, J. F. Minder C. e Titus D. M. P. (1991) "Systems development in information systems research", In: Journal of management information systems, v.7, n.3, p. 89-106.

Scholl, H. J. e Klischewski, R. (2007) "E-government integration and interoperability: Framing the research agenda", In: International Journal of Public Administration, v. 30, n. 8-9, p. 889-920.

Schreiber, G. e Yves, R. (2014), RDF 1.1 Primer, W3C working group note.

Senado Federal (2016) "Portal do Orçamento - Senado Federal - Glossário", https://www12.senado.leg.br/orcamento/glossario, Fevereiro/2019.

Secretaria de Orçamento Federal (2013) "Modelo Ontológico da Classificação das Despesas do Orçamento Federal Brasileiro", http://vocab.e.gov.br/2013/09/loa, Fevereiro/2019.

Suárez-Figueroa, M. C. Gómez-Pérez, A. Motta, E. e Gangemi, A. (2012), Ontology Engineering in a Networked World, Springer Berlin Heidelberg.

Tesouro Nacional (2016a) "Tesouro Nacional - Glossário", http://www.tesouro.gov.br/pt/-/glossario, Fevereiro/2019.

Tesouro Nacional (2016b) "Tesouro Nacional - Execução Orçamentária", http://www.tesouro.fazenda.gov.br/pt_PT/execucao-orcamentaria, Fevereiro/2019. 